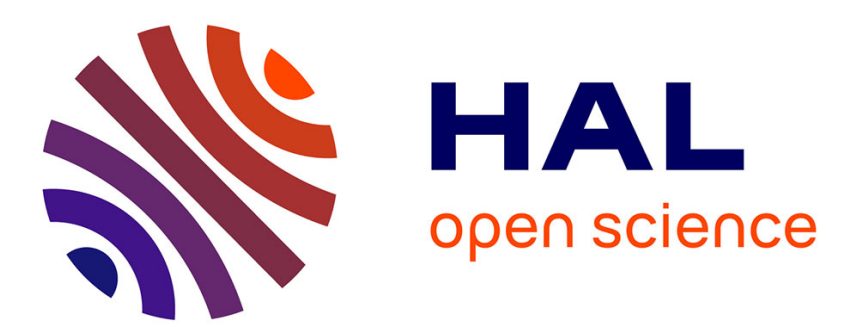

\title{
On-site contactless surface analysis of Modern paintings from Galleria Nazionale (Rome) by Reflectance FTIR and Raman spectroscopies
}

\author{
Diana Mancini, Aline Percot, Ludovic Bellot-Gurlet, Philippe Colomban, \\ Paola Carnazza
}

\section{To cite this version:}

Diana Mancini, Aline Percot, Ludovic Bellot-Gurlet, Philippe Colomban, Paola Carnazza. On-site contactless surface analysis of Modern paintings from Galleria Nazionale (Rome) by Reflectance FTIR and Raman spectroscopies. Talanta, 2021, 227, pp.122159. 10.1016/j.talanta.2021.122159 . hal03141759

\section{HAL Id: hal-03141759 \\ https://hal.science/hal-03141759}

Submitted on 9 Apr 2021

HAL is a multi-disciplinary open access archive for the deposit and dissemination of scientific research documents, whether they are published or not. The documents may come from teaching and research institutions in France or abroad, or from public or private research centers.
L'archive ouverte pluridisciplinaire HAL, est destinée au dépôt et à la diffusion de documents scientifiques de niveau recherche, publiés ou non, émanant des établissements d'enseignement et de recherche français ou étrangers, des laboratoires publics ou privés. 
archives-ouvertes

\title{
On-site contactless surface analysis of Modern paintings from Galleria Nazionale (Rome) by Reflectance FTIR and Raman spectroscopies
}

\author{
Burcu Kırmızı, Jean-Baptiste Clais, Michele Gironda, Philippe Colomban
}

\section{To cite this version:}

Burcu Kırmızı, Jean-Baptiste Clais, Michele Gironda, Philippe Colomban. On-site contactless surface analysis of Modern paintings from Galleria Nazionale (Rome) by Reflectance FTIR and Raman spectroscopies. Journal of Cultural Heritage, Elsevier, 2020, 46, pp.82-94. 10.1016/j.culher.2020.06.008 . hal-03145914

\section{HAL Id: hal-03145914 \\ https: / hal.sorbonne-universite.fr/hal-03145914}

Submitted on 18 Feb 2021

HAL is a multi-disciplinary open access archive for the deposit and dissemination of scientific research documents, whether they are published or not. The documents may come from teaching and research institutions in France or abroad, or from public or private research centers.
L'archive ouverte pluridisciplinaire HAL, est destinée au dépôt et à la diffusion de documents scientifiques de niveau recherche, publiés ou non, émanant des établissements d'enseignement et de recherche français ou étrangers, des laboratoires publics ou privés. 
On-site contactless surface analysis of Modern paintings from Galleria Nazionale (Rome) by Reflectance FTIR and Raman spectroscopies

Diana Mancini ${ }^{1,2}$, Aline Percot ${ }^{1}$, Ludovic Bellot-Gurlet $^{1}$, Philippe Colomban $^{1}$, Paola Carnazza ${ }^{2}$

1 Sorbonne Université, CNRS, De la Molécule aux Nano-Objets: Réactivité, Interactions et Spectroscopies, MONARIS UMR8233, 4 Place Jussieu, 75005 Paris, France.

${ }^{2}$ Galleria Nazionale d'Arte Moderna e Contemporanea viale delle Belle Arti 131, 00197 Roma, Italy.

\section{Corresponding author :}

Aline Percot

Aline.percot@sorbonne-universite.fr 


\title{
Highlights:
}

- Non-invasive mobile approach to characterise artist materials implemented in Modern paintings

- Validation of Specular Reflectance Infrared Spectroscopy analyses to identify paint binders

- Combination of Raman and infrared spectroscopy for identifying Modern paints binders and pigments

- Contactless spectroscopic identification of the binders and pigments of polymeric paints

- On-site analytical study of artworks by German and Italian painters of the 1960s

\begin{abstract}
. Seven artworks representing the diversity of paints used around the 1960s and created by German and Italian painters (J. Albers, A. Bonalumi, L. Boille, T. Scialoja and M. Schifano) were studied onsite at the Galleria Nazionale d'Arte Moderna (Rome) with mobile instruments. We present a methodology based on Specular Reflectance Infrared Spectroscopy (SR-FTIR) adapted to unvarnished paintings. Complementary measurements have been performed by Raman spectroscopy. Characteristic bands regarding as-recorded infrared reflectance spectra and Kramers-Kronig Transformationconverted absorbance spectra are identified according to literature and reference spectra recorded on representative commercially available paints. To distinguish the different binders by SR-FTIR, we propose spectroscopic markers as the comparison of the intensity of carbonyl band around 1730-1735 $\mathrm{cm}^{-1}$ with bands at $\sim 1160$ (for acrylic), $\sim 1230$ (for PVAc), and $1270 \mathrm{~cm}^{-1}$ (for alkyds). On the other hand, oil/resin binders are characterized by intense and thin $\mathrm{vCH}_{2}, \mathrm{vCH}_{3} \mathrm{IR}$ absorption bands around 2920-2850 $\mathrm{cm}^{-1}$, combined with an intense $1260 \mathrm{~cm}^{-1}$ band and a characteristic concave cradle shape (between ca. 1750 and $1260 \mathrm{~cm}^{-1}$ ). The results obtained establish the relevance of the implemented mobile non-invasive infrared spectroscopy analytical approach by successfully identifying acrylic, vinylic, oil media and enamel paints, with or without opacifiers, which is supplemented by Raman analyses for pigment identification.
\end{abstract}

Keywords: Infrared spectroscopy; specular reflectance; SR-FTIR; Raman spectroscopy; non-invasive analyses; on-site analysis; binders; painting; Modern Art.

\section{CRediT author statement}

Diana Mancini: Conceptualization, Methodology, Investigation, Validation, Visualization, Resources, Roles/Writing - original draft; Writing - review \& editing, Funding acquisition; Aline Percot, Ludovic Bellot-Gurlet, Philippe Colomban: Methodology, Investigation, Validation, Visualization, Roles/Writing - original draft; Writing - review \& editing; Paola Carnazza: Resources, Writing review \& editing. 


\section{Introduction}

The identification of binding media used in Modern Art paintings is required for establishing preventive conservation policies, or to document the artist's choices for each work of art in relation to the history of his production. For the pre- $19^{\text {th }}$ century paintings, artists used as binders only a few natural substances such as oils, resins, proteins or polysaccharides. Starting from the middle of the $19^{\text {th }}$ century the established practices of workshops and natural "traditional binders" were challenged by the availability of commercially available paint tubes. During the $20^{\text {th }}$ century artists have experienced various new products based on industrial polymers, leading to a diversification of materials and aesthetic aspects thus possible. Besides the binders, the development of chemistry also concerns pigment synthesis. Because of the complexity of modern paint formulations and the multifaceted visual effects they produce, an analytical approach is required to properly identify the binders used in each artwork.

For respecting the artworks conservation and in the absence of scheduled restoration, non-invasive analytical approaches are mandatory. Moreover, they must be simple to implement in the context of museums or storage spaces. For about a decade, spectroscopic techniques have met these requirements with continuous progress in the miniaturization of devices or the possibility of multiplying the measurements (i.e. imaging). For the characterization of organic binders, elemental analysis (such as X-ray Fluorescence Analysis - XRF or Laser Induced Breakdown Spectroscopy - LIBS) is not particularly selective, unlike molecular spectroscopy: infrared and Raman. More broadly, these latter techniques have become reference analyses for characterizing pigments and dyes, but also polymers chemistry and physical organization. They are therefore relevant for the analysis of modern polymeric paintings binders and they can be implemented on-site and non-invasively.

Micro-Raman spectroscopy performed at the laboratory on micro-samples giving access to the stratigraphy of the painting is well-known as an effective tool for identifying the molecular structure of mainly pigments and dyes in illuminated manuscripts, ancient easel or wood paintings (see for example: [1] [2] [3]). In this way a large number of inorganic and organic pigment materials were identified in various contexts (for instance: [4] [5] [6] [7] [8] [9] [10] [11] [12]). With the development of portable instruments in recent years, studies are regularly conducted without sampling to identify pigments and dyes (for example: [13] [3] [14]). Raman spectroscopy is not readily relevant for the identification of binders (mainly because of their fluorescence which hamper the collection of significant spectra or because of the intense Raman diffusion of pigments), and therefore chromatographic techniques (which require sampling, f.i. [15]) or FTIR must be used [16] [17].

Regarding studies of Modern Art paintings which are the aim of the present work, specific studies have been conducted e.g. for Francis Picabia [12], Pablo Picasso and Jasper Johns works [10][18] and more recently Giuseppe Capogrossi [19]. However analytical studies of the works of art belonging to this period and especially to more recent periods to study their techniques and materials are still scarce, while the diversification of possible practices and products raises specific challenges.

Wishing to proceed on-site in a non-invasive way, in this work we established an approach based on portable infrared spectroscopy in specular reflectance mode (SR-FTIR) partly completed by Raman spectroscopy to collect information focussed on binders, and if/when possible on pigments and dyes. The great advantages are 
the affordability and the versatility of implementation of such a mobile IR instrument, as well as its ability to provide valuable information, which we will highlight in this study. This type of FTIR mobile spectroscopy has been already used for lacquer ware [13], Japanese prints [20], ancient manuscripts and wood panel paintings [21] [22]. Few studies use reflectance FTIR on modern masterpieces (for example: [23] [24] [19][25]). In order to provide infrared signatures that can be easily identified with comparison with reference mock-up samples prepared using commercially available products (see mock-up samples in Supplementary Materials) and with literature commonly expressed in absorbance or transmittance, we chose to firstly apply the Kramers-Kronig transformation to specular reflectance spectra recorded. Measurements by portable Raman spectroscopy involving excitations at 532 and $785 \mathrm{~nm}$ were also used to complete the characterization of paints by identifying their pigments. To demonstrate the relevance of the proposed approach, we conducted a measurement campaign [26] on a selection of 7 artworks from the collection of the Galleria Nazionale d'Arte Moderna (Rome) ${ }^{1}$ expected to represent the diversity of paints binders used from the 1960s. These were created by five German or Italian painters active in Op-art, Arte Informale, Expressionism Abstracted, and Post-modernism schools: Josef Albers $(1888-1976)^{2}$, Agostino Bonalumi (1935-2013) ${ }^{3}$, Luigi Boille (1926-2015) ${ }^{4}$, Toti Scialoja $(1914-1998)^{5}$ and Mario Schifano (1934-1998) ${ }^{6}$. In order to explore the diversity of possible situations and challenge the proposed approach we choose various paintings made on different supports/techniques according to museum records, including 3D shapes.

\section{Material and methods}

\subsection{Artworks selected}

Following the information resulting form the visual analysis and art history research presented in the catalogue “Galleria Nazionale d'Arte Moderna \& MAXXI: Le collezioni 1958-2008” [27], we have chosen artworks indicated to have been produced with diversified families of binding media belonging to acrylic, vinylic, tempera, oil and enamel types, in order to challenge the proposed approach on a variety of modern paintings, having either flat, non-planar, matt or glossy surfaces. These paintings belong to the Contemporary Art collection of the "Galleria Nazionale d'Arte Moderna e Contemporanea (GNAM)" of Rome (Italy). They were realized by artists active in the Rome area during the second half of the Twentieth Century.

Presented by artists, the seven paintings analysed are the following (with date of production and binder attribution taken from museum records, Table 1) [27]:

- From Josef Albers, Homage to the square (1958), acrylic on hardboard (masonite), $60.5 \times 60.5 \mathrm{~cm}^{2}$, inv. 5393 (Fig 1-1).

\footnotetext{
${ }^{1}$ https://lagallerianazionale.com/

${ }^{2}$ https://en.wikipedia.org/wiki/Josef_Albers; http://www.artnet.com/artists/josef-albers/

${ }^{3}$ https://en.wikipedia.org/wiki/Agostino_Bonalumi; http://www.artnet.com/artists/agostino-bonalumi/

${ }^{4}$ https://en.wikipedia.org/wiki/Luigi_Boille; http://www.artnet.com/artists/luigi-boille/

${ }^{5}$ https://it.wikipedia.org/wiki/Toti_Scialoja; http://www.artnet.com/artists/toti-scialoja/

${ }^{6}$ https://en.wikipedia.org/wiki/Mario_Schifano; http://www.artnet.com/artists/mario-schifano/
} 
- From Agostino Bonalumi, three monochromes: Blu 13/B (1967), acrylic on shaped, 149,5x119,5x26 cm³, inv. 5460 (Fig. 1-2); Azzurro (1993), Vinylic tempera, 114x146x9 cm³ inv. 15092 (Fig. 1-3); Oggetto $n$. 23 (1965), enamel on shaped canvas, 120x90x5 cm³ inv. 15090 (Fig. 1-4). A more recent work by this artist ("Azzurro") was included in the study in order to explore the materials he may have used.

- From Toti Scialoja, Intermittenze 1-2-3 (1966), vinylic on 3 distinct canvas each of 200x160 $\mathrm{cm}^{2}$, inv. 733 (Fig. 1-8).

- From Luigi Boille, Elementare Complesso (1965), oil on canvas, 200x160 cm², inv. 5434 (Fig. 1-5).

- From Mario Schifano, Incidente D662 (1963), enamel, charcoal, paper on canvas, 160x120 cm², inv. 5362 (Fig. 1-6).

Table 1: Description of the work of art studied and their binder attribution.

\begin{tabular}{|l|l|l|l|l|l|}
\hline Paintings & & Binders \\
\hline Author & Name & Surface & Fig. & After catalog* & After this study \\
\hline Josef Albers & Homage to the square & Mat & $1-1$ & Acrylic & Acrylic \\
\hline \multirow{3}{*}{ Agostino Bonalumi } & Blu 13/B & Glossy, 3D & $1-2$ & Acrylic & Vinyl \\
\cline { 2 - 6 } & Azzurro & 3D & $1-3$ & Vinylic tempera & Not identified \\
\cline { 2 - 6 } & Oggetto n. 23 & Semi-glossy, 3D & $1-4$ & Enamel & Vinyl \\
\hline Toti Scialoja & Intermittenze 1-2-3 & Mat & $1-8$ & Vinylic & Vinylic + ? \\
\hline Luigi Boille & Elementare Complesso & Glossy & $1-5$ & Oil & Oil \\
\hline Mario Schifano & Incidente D662 & Mat & $1-6$ & Enamel & Enamel + Vinylic \\
\hline
\end{tabular}

* from [27]

\subsection{Identification of the artistic technique}

As previously mentioned, throughout the twentieth century new synthetic polymers have been developed, many of which have been used as binding media in modern paints. These efficient paints were widely used by the artist community. These synthetic binding media, most notably acrylic, alkyd, and polyvinyl acetate, have complex and often poorly documented formulation [28]. Thanks to their properties they have changed the artistic gesture and vocabulary in the field of art, but nowadays these materials may complicate the conservation strategies that must be adapted.

In this study, we will focus on the five classes of binding media above mentioned and used in the paintings studied, which are named according to the museum records: acrylic, vinylic, oil, tempera and "enamel" binders. First of all, they need to be more precisely defined from a chemical point of view because the same denomination could refer to various chemical compositions depending on whether one is in the commercial or the artistic field. Indeed, the term "acrylic binder" concerns a large family of polymers involving different monomers and functional groups. There are two main types, acrylic solution (i.e. soluble in organic or aqueous solvents) and acrylic emulsion (i.e. dispersed in the solvent). The first artists' acrylic emulsion paint to appear was Liquitex® (Permanent Pigments) in 1956, which was widely adopted by artists from the 1960's onwards. The most important classes of acrylic paints are formed by a group of copolymer, between methyl methacrylate (MMA), ethyl acrylate (EA) and n-butyl acrylate (nBA). Beyond their use by artists, some of them also have applications in the restoration field as varnishes, lacquers, adhesives, and consolidating [29]. 
In this study, we assume that vinyl paints refers to polyvinyl acetate (PVAc) emulsions that became available in the late 1940's. It has remained the main type of binder used in interior emulsion house paint in many European countries (with the term vinyl emulsion). PVAc can be used alone or modified by, maleate, fumarate or ethylene esters, which makes the naming and identification more complex [30]. The current PVAc artist paint called Flashe ${ }^{\circledR}$ from Lefranc \& Bourgeois, is formulated as an emulsion and a waterproof film once dried. So, these emulsions can also be named "tempera" in reference to the properties of the "traditional tempera" (i.e.water egg based emulsion).

Alkyd paints (also called "enamel”) are oil-modified polyester paints introduced in the late 1930's. The term alkyd comes from its two main components, a poly alcohol and a poly acid. The vast majority of alkyd house paints results from the condensation polymerisation of three compounds: polyalcohols, polybasic acids and fatty acids, typically glycerol, phtalic anhydride and linoleic acid.

The binder medium can also be called by the name of the used technique, such as oil or tempera. Oil binding medium is mainly composed of fatty acids originating from vegetable oils as traditional drying oils (linseed, poppy seed and walnut oil), other drying, semi and non-drying lipidic binders became employed with time as safflower, sunflower, castor and cotton-seed oils [31] [32] [33]. As previously mentioned, the case of tempera is more complicated and its composition can be very different from one artist to another [34]. Tempera generally refers to an emulsion involving egg yolk or the whole egg, but other recipes involve replacement with polysaccharides, proteins or synthetic polymers. Among natural binders, the most commonly used for commercial tempera is a polysaccharide material (most often as a low cost starch derivative-dextrin with a simple chemical structure, or more complex gum exudates as arabic gum). In the case of synthetic polymers commercialised as tempera, acrylic and vinylic medium emulsified in water are found (as acrylic/vinylic tempera). Generally, tempera presents a matt aspect that can be more easily distinguishable from the paints described above.

To establish a reference vibrational spectra set corresponding to these different classes of materials, some mockup samples have been prepared using the following commercial paints. For tempera we used: Extra fine quality® from Royal Talens (colours: grey, silver) (Netherlands); for acrylic we used: Acrylic professional and basic ${ }^{\circledR}$ from Liquitex (white colour) (France); for vinylic paints, we used: Flashe ${ }^{\circledR}$ from Lefranc \& Bourgeois (blue colour) (France). The reference sample studied for enamel was Rainbow: Retouching model enamels ${ }^{\circledR}$ from Maimeri (Italy) (white colour). Samples were prepared by applying one layer of paint on glass slides and leaving them drying for one week.

\subsection{Instruments and methods}

Portable instruments were installed in a storage room of the GNAM museum and implemented directly on artworks (Fig. 1). Thanks to the reduced size of the equipment, an appropriate positioning as perpendicular as possible in front of the analysed areas can be easily achieved, whatever the size or geometry of the painting using a tripod, a lifting support or a table when the painting can be positioned with an easel.

Infrared spectroscopy in Specular Reflectance mode 
The contactless infrared spectroscopy analyses were performed in a specular reflectance (SR) mode with the Alpha portable spectrometer (Bruker Optics) equipped with the specular reflection module. This spectrometer is based on an interferometer with a $\mathrm{KBr}$ beam splitter associated to a Globar source (SiC) and a DLaTGS (Deuterated Lanthanum $\alpha$-alanine doped triglycine sulphate) detector. Within this SR module a built in videocamera gives a magnified view of the measurement area and allows exact positioning of the spectrometer in front of the sample by displacing the whole instrument. The IR beam is focused and collected by a set of mirrors with a $45^{\circ}$ incidence angle, promoting the collection of the specular reflection. The beam diameter focused at the sample is about $5 \mathrm{~mm}$ at the working distance of $15 \mathrm{~mm}$. The distance to the object to be analysed is achieved by gradually moving the instrument with the hands or with a microscopic stage until the video image is focused (Fig. 1-10). Background (acquired on a golden mirror) and spectra were collected between 3600 and $650 \mathrm{~cm}^{-1}$ with a resolution of $4 \mathrm{~cm}^{-1}$ by accumulating 128 scans (a few minutes). All samples were analyzed in several points to assess their homogeneity and the analytical reproducibility. The residual atmospheric contribution in recorded IR spectra (often weakly present despite the background correction performed) was corrected using the $\mathrm{H}_{2} \mathrm{O} / \mathrm{CO}_{2}$ compensation function of the OPUS software (Bruker) that also drives the spectrometer operation.

In the SR-FTIR analyses, the reflectance spectra showed a large amount of bands with a pole shape profile. According the general description of complex susceptibility [35], the characteristic wavenumber associated to a conventional absorbance band is the inflection point as indicated in Fig 6 and S1a. Determination of these bands positions are obvious for narrow poles (inflexion point is straightforward) but not for broader features, especially if different contributions overlap. The intensity of the infrared light actually reflected depends on the absorption behaviour of the sample. For wavenumbers strongly absorbed, the reflected signal is more intense compared to non-absorbing spectral regions. Pseudo-absorbance spectra are calculated from SR spectra by applying the Kramers-Kronig Transformation (KKT) algorithm [36] included in the OPUS software. This transformation is performed in order to provide infrared signatures that are easier to compare with literature spectra conventionally recorded in transmission or ATR modes. However, the use of the KKT transformation to obtain pseudoabsorbance spectra presupposes that the physical state of the surface (roughness) does not produce a significant diffuse reflection. The device used to record the reflectance spectra is designed to preferentially collect its specular part, but according to the variable surface characteristics of analysed samples a "perfect" pseudoabsorbance spectrum may not be obtained, thus introducing spectral distortions that may hinder the interpretation of the spectra. Mock-up samples were also analysed at the laboratory by SR-FTIR with the same mobile instrument as well as by Attenuated Total Reflectance (ATR) on micro-samples using the same spectrometer but equipped with its ATR-FTIR accessory (based on a diamond ATR crystal) for comparison and assignment confirmation (see Figs S1).

\section{Raman spectroscopy}

Additional measurements were performed using two portable fibre optic-based instruments: the HE532 and the HE785 micro-Raman spectrometers from Horiba Jobin Yvon. The slight weight and space requirement make comfortable the Raman on-site measurements, to which, however, a stable positioning system (here a tripod) for the Raman probe must be added (see Figure 1-5). Both spectrometers are based on a fixed parabolic grating (920 lines/mm for the HE532 and 685 lines/mm for the HE785), and equipped with charge coupled device (CCD) detector cooled by Peltier effect. They are designed to record a fixed spectral window between 80 and $3200 \mathrm{~cm}^{-1}$ 
with a spectral resolution of about $5 \mathrm{~cm}^{-1}$. A $785 \mathrm{~nm} 300 \mathrm{~mW}$ diode (Process Instruments) and a Ventus $532 \mathrm{~nm}$ $100 \mathrm{~mW}$ (Laser Quantum) YAG laser were coupled to the spectrometers described above, as well as 785 and 532 $\mathrm{nm}$ remote SuperHead optical heads containing the corresponding edge filters for Rayleigh filtering. Measurement is focused using a video camera incorporated to the $785 \mathrm{~nm}$ SuperHead, and by eye focus control of the for the $532 \mathrm{~nm}$ beam. The objectives used were, for HE532 a super-long working distance $(17 \mathrm{~mm})$ Nikon x50 (N.A. $=0.45$ ), and for HE785 a long working distance $(7 \mathrm{~mm}$ ) infrared Leica $\mathrm{x} 40$ (N.A. $=0.45$ ). These objectives give a laser beam spot of about $3 \mu \mathrm{m}$ and $18 \mu \mathrm{m}$ respectively. To prevent any damage to the paints, the lasers powers at the sample were carefully adjusted and measured around $100 \mu \mathrm{W}$ for $532 \mathrm{~nm}$ and $300 \mu \mathrm{W}$ for the less energetic $785 \mathrm{~nm}$. The typical measurement time per spectrum was around 2 min on site in order to optimise the session time.

Some complementary measurements on mock-up samples have been carried out in the laboratory using a benchtop RFS 100/S FT-Raman spectrometer coupled to a Ramanscope III (Bruker Optics) (Fig. S2). The 1064 $\mathrm{nm}$ exciting wavelength (Nd:YAG laser) avoids (most of) the fluorescence signal from the samples thanks to its low excitation energy and therefore improve the sightlines of the Raman bands.

\section{Results and discussion:}

\subsection{Infrared spectroscopy analyses}

First of all, acquisition of accurate infrared reflectance spectra in museum environment, on imperfect surfaces (from a geometry or surface state point of view) requires cautions when recording spectra and analysing the results obtained. The multilayered geometry, the thickness of the layers, the refractive index of the binder, the incident wavelength... affect the recorded spectrum. Practical implementation factors such as IR beam angle of incidence are also important because for specular reflection (which has to be measured at or near normal incidence) the perpendicular positioning of instrument can significantly affect the measurement.

Albers, Bonalumi, Scialoja, Boille and Schifano artworks are presented in Fig. 1. On-site KKT SR-FTIR representative spectra are given in Fig. 2 to 5 and S3, each of which refers to spectra recorded on different colours and hues after grouping by artists. Selected as-recorded reflectance spectra are shown in Fig. 6. For easier comparison with the existing databases and literature, chemical nature of the binder is first identified thanks to the KKT transformed spectra presented as pseudo-absorbance spectra.

Despite the theoretical preconceptions constraining the efficiency of IR specular reflectance on "raw" surface, SR-FTIR spectra were successfully obtained for all the artefacts, regardless of whether they are more or less matt or glossy as well as flat or not (Table 1, Fig. 2 to 6). The obtained reflectance spectra (Fig. 6) exhibit distorted patterns compared to traditional transmission FTIR or ATR spectra. In a first approach, SR-FTIR spectra were corrected with the Kramers-Kronig transformation (Fig. 2 to 5 and S3). The robustness of the comparison was assessed by measurements performed in the lab on mock-up samples enabling the comparison between Specular Reflectance spectra and more standard ATR ones. Fig. S1 presents spectra from the same mock-up samples obtained before and after the KKT transformation of reflectance spectra (Fig. S1a and b) and spectra recorded using ATR (Fig. S1c). This underlines that major absorbance bands have almost the same positions and relative intensities. One can notice that only the large bands around $3100 \mathrm{~cm}^{-1}$ have been inadequately corrected by 
giving a decreasing baseline, and therefore cannot be considered for interpretation (Fig. S1). The relevant spectral features are observable on both treated SR-FTIR spectra and ATR-IR ones. This demonstrates for such modern paintings the ability to obtain meaningful infrared signatures of the sample chemistry by contactless infrared spectroscopy (i.e. spectra not significantly distorted by the surface characteristics). Tables S1 to S4 comparing the main IR characteristic bands were established for different commercial paints in agreement with the literature. Analyses of the artworks are presented and discussed hereafter.

Josef Albers's "Homage to the square" (1958) painting (Fig. 1-1): representative SR-FTIR-spectra from all colours showed in Fig. 2 are similar and have the equivalent pattern with the following markers: 1734, 1450, 1383, 1235 and $1160 \mathrm{~cm}^{-1}$, and the stretching modes of $-\mathrm{CH}_{2} / \mathrm{CH}_{3}$ groups can also be observed around 2900 $\mathrm{cm}^{-1}$. This is in perfect agreement with reflectance spectra obtained for the polyacrylic binder reference spectra shown in Fig. S1. The spectra are dominated by two characteristic intense bands at $1734 \mathrm{~cm}^{-1}$ and $1160 \mathrm{~cm}^{-1}$ respectively attributed to $\mathrm{C}=\mathrm{O}$ and $\mathrm{C}-\mathrm{O}$ stretching vibrations.

Luigi Boille's "Elementare Complesso" (1965) painting (Fig. 1-5): all the spectra obtained (Fig. 3) present the same pattern for all the analysed colours, which is characterised by a concave cradle shape in-between ca. 1745 and $1260 \mathrm{~cm}^{-1}$. The collected spectra display the following spectral features: $\mathrm{CH}_{2}$ stretching bands are visible at 2920 and $2850 \mathrm{~cm}^{-1}$ typical for saturated hydrocarbons along with the respective bending vibrations at 1465 and $1380 \mathrm{~cm}^{-1}$, an intense $\mathrm{C}=\mathrm{O}$ band typical for triglyceride esters at $1745 \mathrm{~cm}^{-1}$, all of which point to a partially hydrolyzed oil binder or varnish [37] [33]. Knowing that SR-FTIR is a surface analysis the presence of an oily finishing layer cannot be excluded. Moreover, the glossy aspect can support this hypothesis.

Agostino Bonalumi's "Blu 13/B" (1967), "Azzurro" (1993) and "Oggetto n. 23" (1965) monochromes (Fig. 1-2, 1-3 and 1-4). The binder medium detected is the same for two of the three paintings: in "Blu 13/B" (colour: blue) and "Oggetto n. 23" (colour: black). This is underlined by characteristic bands that are observed around 2920 and 2840, 1734, 1371, 1237, 1125, 1020 and $940 \mathrm{~cm}^{-1}$ (Fig. 4). Attribution to the PVAc binder for these two artworks is made according to Table S2, taking into account the strong intensity of the band at about $1237 \mathrm{~cm}^{-1}$ associated to the $v(\mathrm{C}-\mathrm{C}(=\mathrm{O})-\mathrm{O})$ mode. In term of presence of bands, there are similarities with the vibrational spectrum of polyacrylic film (Table S1), however differences can be highlighted by observing their relative intensities. For PVAc films, spectra are dominated by two characteristic intense bands at $1734 \mathrm{~cm}^{-1}$ and $1237 \mathrm{~cm}^{-}$

${ }^{1}$ with about the same intensity, and respectively attributed to $\mathrm{C}=\mathrm{O}$ and $\mathrm{C}-\mathrm{C}(=\mathrm{O})-\mathrm{O}$ stretching vibrations. The spectrum corresponding to "Azzurro" (colour: light blue) is of bad quality, may be due to the presence of a white opacifier $\left(\mathrm{CaCO}_{3}\right.$, pointed out by a large band around 1420 and narrow bands at 725 and $\left.874 \mathrm{~cm}^{-1}\right)$ and/or because of the matt aspect of the painting (due to the presence of this opacifier?) and/or as a result of the nonperpendicular measurement collection angle resulting from the 3D geometry of the artwork. This latter hypothesis can be ruled out as several measurement positions were tested without any improvement in the spectra obtained.

Spectra registered on Mario Schifano's "Incidente D662" (1963) (Fig. 1-6) are shown in Fig. 5. The spectra obtained for red, black and gray paints present similarities with intense vibrational bands at 2856, 2928, 1735, $1270,1190,1125$ and $1080 \mathrm{~cm}^{-1}$. The alkyd binder medium is recognized by its characteristic FTIR-spectrum containing a hydroxyl group band at $3455 \mathrm{~cm}^{-1}$ (broad band), $\mathrm{CH}_{2}$ asymmetric and symmetric stretching and bending bands at 2927,2857 and $1461 \mathrm{~cm}^{-1}$ respectively, a strong $\mathrm{C}=\mathrm{O}$ stretching band around $1729 \mathrm{~cm}^{-1}$ with 
the C-O fingerprint bands at $1270 \mathrm{~cm}^{-1}$ (strong and slightly rounded), likely due to the esters. The presence of aromatic rings, maybe related to phthalic acids, is suggested by the occurrence of the sharp doublet aromatic stretching bands at 1600 and $1580 \mathrm{~cm}^{-1}$, the strong unsaturated ring in-plane deformation band at $1071-73 \mathrm{~cm}^{-1}$ and the out-of-plane deformation bands at 743 and $720 \mathrm{~cm}^{-1}$ [38] (Table S4). For the black and red paints, the intense band at $1080 \mathrm{~cm}^{-1}$, the bands at 1190, 978, 635 and $606 \mathrm{~cm}^{-1}$, indicate the presence of barium sulphate. The spectrum pattern obtained for the orange colour is different, and presents similarities with vinylic commercial paints (Table S2). Both the pointed shape of the band at $1230 \mathrm{~cm}^{-1}(v(\mathrm{C}-\mathrm{C}(\mathrm{O})-\mathrm{O}))$ and its high intensity with respect to that at $1735 \mathrm{~cm}^{-1}(\mathrm{C}=\mathrm{O})$ confirm this assumption. The bands associated with methyl and $\mathrm{CO}$ at $1370 \mathrm{~cm}^{-1}$ and $1015 \mathrm{~cm}^{-1}$ can also be detected.

For Toti Scialoja's "Intermittenze 1-2-3" (1966) (Fig 1-8) from its different colours 2 different spectral patterns are obtained on Fig. S3. Yellow, pink and red paints present the characteristic spectral features of PVAc (Table S2) whereas grey and white paints present bad quality spectra. This can be attributed to different factors influencing measures as the presence of white opacifier and matt appearance of grey and white pictorial surfaces. The white opacifier could be lead white $\left(2 \mathrm{PbCO}_{3} \cdot \mathrm{Pb}(\mathrm{OH})_{2}\right)$, in relation with the 765,840 and $1380 \mathrm{~cm}^{-1}$ observed bands.

The binders identified for all the studied artworks are summarized in Table 1. Most of the polymeric binders discussed in this study contain the same chemical groups, based on alkyl group, $-\mathrm{CH}_{3},-\mathrm{CH}_{2},-\mathrm{CH}$ (stretching IR absorption around 2975-2850 $\mathrm{cm}^{-1}$, deformation around 1140-1170, 1250, 1360-1380 and 1430-1470 $\mathrm{cm}^{-1}$ ), carbonyl group (1700-1750 $\left.\mathrm{cm}^{-1}\right)$, C-O $\left(1060-1170 ; 1230-1260 \mathrm{~cm}^{-1}\right)$, C-C... However, we can propose the following simple sets of spectroscopic markers that can be used to quickly differentiate between them.

- Acrylic binders: simultaneous observation of an intense carbonyl band around 1730-1735 $\mathrm{cm}^{-1}$ and an intense band at $1160 \mathrm{~cm}^{-1}$.

- PVAc binders: simultaneous observation of an intense carbonyl band at around 1730-1735 $\mathrm{cm}^{-1}$, and of an intense band at 1230-1235 $\mathrm{cm}^{-1}$. The intensity ratio between both bands is close to 1 .

- Alkyd binders: simultaneous observation of 3 major bands at 1730-1735 $\mathrm{cm}^{-1}, 1270 \mathrm{~cm}^{-1}$ and $1120-1125 \mathrm{~cm}^{-1}$.

- Oil/resin binders present intense and thin $\mathrm{vCH}_{2}$ stretching IR absorption around 2920-2850 $\mathrm{cm}^{-1}$, with intense 1750 and $1260 \mathrm{~cm}^{-1}$ bands and a characteristic concave cradle shape in-between.

Everyone can question the adequacy and necessity of the KKT correction applied on the raw reflectance spectra. We chose to use KKT converted spectra to identify the different types of binders but actually the same conclusions can be drawn without applying KKT. Fig. 6 compares representative as-recorded reflectance spectra for different binders. In this figure we chose intentionally to present good and bad quality spectra. Most of the reflectance spectra observed are of good quality and the inflexion points of the intense "bands" can be pointed out, even if they are more or less deformed from their ideal shape due to the anomalous dispersion of the refractive index. The position of the major bands marked on Fig 6 can be used for binder attribution with respect to the previously mentioned spectroscopic markers. Even for spectra recorded on matt surfaces, the signal is intelligible and relevant, as it can be observed from Albers and Bonalumi paintings. All spectra of the different binders can be discriminated and assigned. However on non flat surfaces as "Azzuro" work (by Bonalumi), no good quality spectrum could be obtained, whatever the position of the spectrometer achieved while repeating the 
measurements. A specificity of the painting itself is perhaps the reason for this poor reflectance response, knowing that this late work of the artist (created in 1993) could therefore have been achieved with a paint significantly different from those of the 1960s.

Although for an analyst used to the interpretation of "classical" infrared spectra (in transmission or ATR) it is easier to work with spectra having been subjected to the KKT transformation, with the adapted references spectra and some practice, the reliable identification of binders can be achieved from the as recorded reflectance spectra (without KKT transformation).

\subsection{Raman spectroscopy analyzes}

Raman spectroscopy is currently widely used to analyze works of art. In principle Raman spectroscopy can be used to analyse both binders and pigments (organic or mineral). However, the strong fluorescence emitted by many organic compounds often hinders their characterisation. This is particularly often the case for organic binders, which are therefore difficult to study by Raman spectroscopy and which can also prevent the study of the pigments they contain. The use of red excitation wavelengths often allows deviation from the spurious fluorescence signal, but high-performance spectrometers with $1064 \mathrm{~nm}$ excitation are still currently limited to laboratory instruments (such as FT-Raman systems). In this work for on-site analyses we used both a spectrometer with one excitation in the green $(532 \mathrm{~nm})$ and another one in the red $(785 \mathrm{~nm})$. As expected, the latter showed the possibility of recording relevant results on more paints. However, with the excitation at $532 \mathrm{~nm}$ relevant spectra could be obtained in some cases, highlighting changes in spectral shapes and/or sensitivity due to resonance effects with some pigments (see Fig. S2). However, we mainly present here the results obtained with the $785 \mathrm{~nm}$ excitation (Fig. S4 to S10). The spectra mainly highlight the presence of the pigments, whose response usually covers that of the binder. On the other hand, the almost single presence of a binder in the analyzed volume (potentially envisaged with microanalysis) generally produces only an intense fluorescence signal that completely covers its Raman scattering. In addition, the very low sensitivity of the CCD detectors in the region around $3000 \mathrm{~cm}^{-1}$ should also be pointed out [39], as they do not allow the intense $\mathrm{CH}$ stretching to be recorded properly (only small bands for some spectra mainly in Fig. S2, S5, S6, S8 and S10).

Another feature of the artworks studied is the presence of some compounds with an extremely intense Raman diffusion that masks all other signals. This is the case of titanium oxides (rutile/anatase) and in particular of the excellent Raman diffuser: anatase, obviously present for some white colours (f.i. T. Scialoja "Intermittenze 1-23", Fig. S7) but also for other colours (f.i. grey, pink and red, T. Scialoja "Intermittenze 1-2-3", fig. S7 and S9).

All pigments that could be identified are listed in Table S6. The identifications where achieved thanks to reference spectra published in the literature [7] [9] [40] [41] underlining the presence of both inorganic (anatase, rutile, carbon black, cinnabar) and organic (PB15, PG7, PO21, PY212, PY34) pigments. Fig. S10 presents Raman analysis of different coloured region of the M. Schifano painting using $785 \mathrm{~nm}$ excitation. 5 intense and clearly different spectra were quickly obtained and allowed the unambiguous identification of the organic and inorganic pigment used (Table S6).

This effective detection of pigments by Raman spectroscopy, however, underlines a low sensitivity to characterise opacifiers present in paints and which have been detected by SR-FTIR spectroscopy (lead/calcium 
carbonates, barium sulphate). This could be explained either by the relative quantities of these different compounds, or by their respective Raman scattering abilities. The first parameter could also be associated with the volumes/surfaces probed by both techniques, with a "more macro" approach for SR-FTIR than for Raman micro-measurements which could explain a better sensitivity to some compounds. However, this underlines the very high complementarity of the two analytical approaches.

\section{Conclusion}

The challenge in this work is to use simple and robust analytical approaches to study Modern art paintings onsite, in a non-destructive way, to characterise their paints and formulations by addressing both their binders and pigments. For this purpose we have combined the use of specular reflectance infrared spectroscopy (SR-FTIR) and Raman spectroscopy thanks to mobile instruments that can be friendly implemented on-site. For the implementation and validation of the proposed protocols we had to address different experimental issues by studying mock-up samples in the lab and a selection of artworks currated at the GNAM (Roma) which represent the diversity of possible situations for this type of works of art.

Relevant infrared spectra were obtained using the contactless specular reflectance infrared spectroscopy (SRFTIR) on various modern paint geometries and compositions without compromising their integrity. Infrared spectroscopy has provided more detailed physicochemical information about binder media compared to Raman spectroscopy, which mainly allows the identification of pigments. The non-invasive study of the binders of the paints used by modern artists, and not only dyes/pigments as is commonly done, provides valuable information on the history of artistic technique but also for preventive and curative conservation strategies.

In J. Albers "Homage to the square" all the hues are obtained using the same acrylic binder medium as is marked in the Catalogue. A. Bonalumi paintings assigned by the Catalogue to acrylic (Blu 13/B) and enamel (Oggetto $n$. 23) are recognized to be made with a vinylic binder medium maybe PVA while for "Azzurro" the identification of medium is prevented by the poor quality of the SR-FTIR obtained spectra. The ascription related to T. Scialoja paintings named "Intermittenze 1-2-3" to a vinyl medium is also confirmed, but also more precisely detailed as polyvinyl polymer maybe PVA. The oil medium/varnish is identified on L. Boille "Elementare Complesso" and has confirmed the attribution made by conservation professionals. The last painting analysed named "Incidente D662", produced M. Schifano, was recognized as being realised by a mixed technique in which the prevalent medium is an alkyd polymer identified on red, black and gray colours, while the orange colour belongs to a vinylic paint. The painting technique "enamel" listed on the Catalogue is therefore defined even more precisely.

Although the approaches developed have shown their performance in establishing the composition of these 1960s paints, we must bear in mind that this non-invasive measurement configuration only explores the top surface of the painting and therefore the possible presence of a varnish layer has to be taken into account. These on site/non-invasive analyses do not provide information on stratigraphy, unlike micro-sampling and crosssectioning. In addition, micro-sample laboratory techniques, whether the same vibrational techniques or other separative techniques such as chromatography, could provide more detailed information on the formulation of these paints and the execution of the artworks. 
But before any invasive analytical approaches, it is mandatory to use strategies that respect the integrity of the artworks. Because this may already provide the required information, or it may guide, direct and limit the microsampling in an integrated strategy of study. In this sense, the approaches proposed in this work could be pertinently implemented to develop studies on the rich heritage of modern art.

\section{Acknowledgements:}

We thank the National Gallery of Modern and Contemporary Art (Rome) for hosting all the partners of the project.

Funding:

This work was supported by the Region of Lazio (Italy) with the grant program "TORNO SUBITO 2015" obtained by Diana Mancini.

Declaration of competing interest:

The authors declare that they have no conflict of interest.

\section{References}

[1] P. Vandenabeele, H.G.M. Edwards, L. Moens, A decade of Raman spectroscopy in Art and Archaeology, Chemical Reviews 107(3) (2007) 675-686.

[2] K. Trentelman, N. Turner, Investigation of the painting materials and techniques of the late-15th century manuscript illuminator Jean Bourdichon, Journal of Raman Spectroscopy 40(5) (2009) 577-584.

[3] E. Stanzani, D. Bersani, P.P. Lottici, P. Colomban, Analysis of artist's palette on a 16th century wood panel painting by portable and laboratory Raman instruments, Vibrational Spectroscopy 85 (2016) 62-70.

[4] C. Coupry, A. Lautié, M. Revault, J. Dufilho, Contribution of Raman spectroscopy to art and history, Journal of Raman Spectroscopy 25(1) (1994) 89-94.

[5] R.A. Goodall, J. Hall, R. Viel, F. Ricardo Agurcia, H.G.M. Edwards, P.M. Fredericks, Raman microscopic investigation of paint samples from the Rosalila building, Copan, Honduras, Journal of Raman Spectroscopy 37(10) (2006) 1072-1077.

[6] H.G.M. Edwards, D.W. Farwell, The conservational heritage of wall paintings and buildings : an FT-Raman spectroscopic study of prehistoric, Roman, mediaeval and Renaissance lime substrates and mortars, Journal of Raman Spectroscopy 39(8) (2008) 985-992.

[7] P. Ropret, S.A. Centeno, P. Bukovec, Raman identification of yellow synthetic organic pigments in modern and contemporary paintings: Reference spectra and case studies, Spectrochimica Acta Part A: Molecular and Biomolecular Spectroscopy 69(2) (2008) 486-497.

[8] P. Vandenabeele, P. De Paepe, L. Moens, Study of the 19th century porcelain cards with direct Raman analysis, Journal of Raman Spectroscopy 39(8) (2008) 1099-1103.

[9] N.C. Scherrer, Z. Stefan, D. Francoise, F. Annette, K. Renate, Synthetic organic pigments of the 20th and 21st century relevant to artist's paints: Raman spectra reference collection, Spectrochimica Acta Part A: Molecular and Biomolecular Spectroscopy 73(3) (2009) 505-524. 
[10] F. Casadio, A. Bezúr, I. Fiedler, K. Muir, T. Trad, S. Maccagnola, Pablo Picasso to Jasper Johns: a Raman study of cobalt-based synthetic inorganic pigments, Journal of Raman Spectroscopy 43(11) (2012) 1761 1771 .

[11] P. Colomban, The destructive/non-destructive identification of enameled pottery, glass artifacts and associated pigments, Arts 2(3) (2013) 77-110.

[12] M. Kokkori, M.-O. Hubert, N. Balcar, G. Barabant, K. Sutherland, F. Casadio, Gloss paints in late paintings by Francis Picabia: a multi-analytical study, Applied Physics A 122(1) (2016) 16.

[13] P. Colomban, D. Mancini, Lacquerware pigment identification with fixed and mobile Raman microspectrometers: a potential technique to differentiate original/fake artworks, Arts 2 (2013) 111-123.

[14] F.C. Agnoletto, L. de Ferri, D. Bersani, G. Pojana, The Jacopo Tintoretto "Wedding Feast at Cana": A noninvasive and multi-technique analytical approach for studying painting materials, Spectrochimica Acta Part A: Molecular and Biomolecular Spectroscopy 229 (2020) 117954.

[15] I. Bonaduce, E. Ribechini, F. Modugno, M.P. Colombini, Analytical approaches based on Gas Chromatography Mass Spectrometry (GC/MS) to study organic materials in artworks and archaeological objects, Topics in Current Chemistry 374(1) (2016) 6_1-37.

[16] T.J.S. Learner, P. Smithen, J.W. Krueger, M.R. Schilling, Modern paints uncovered: proceedings from the Modern Paints uncovered symposium, Getty Conservation Institute, Los Angeles, 2007.

[17] F. Rosi, L. Cartechini, D. Sali, C. Miliani, Recent trends in the application of Fourier Transform Infrared (FT-IR) spectroscopy in Heritage Science: from micro- to non-invasive FT-IR, Physical Sciences Reviews 4(11) (2019) 20180006.

[18] F. Casadio, C. Miliani, F. Rosi, A. Romani, C. Anselmi, B. Brunetti, A. Sgamellotti, J.-L. Andral, G. Gautier, Scientific investigation of an important corpus of Picasso paintings in Antibes: new insights into technique, condition, and chronological sequence, Journal of the American Institute for Conservation 52(3) (2013) 184-204.

[19] J. La Nasa, P. Moretti, E. Maniccia, S. Pizzimenti, M.P. Colombini, C. Miliani, F. Modugno, P. Carnazza, D. De Luca, Discovering Giuseppe Capogrossi: study of the painting materials in three works of art stored at Galleria Nazionale (Rome), Heritage 3 (2020) 965-984. .

[20] C. Biron, G. Le Bourdon, J. Pérez-Arantegui, L. Servant, R. Chapoulie, F. Daniel, Probing some organic ukiyo-e Japanese pigments and mixtures using non-invasive and mobile infrared spectroscopies, Analytical and Bioanalytical Chemistry 410(27) (2010) 7043-7054.

[21] B. Brunetti, C. Miliani, F. Rosi, B. Doherty, L. Monico, A. Romani, A. Sgamellotti, Non-invasive Investigations of Paintings by Portable Instrumentation: The MOLAB Experience, Topics in Current Chemistry 374(1) (2016) 10.

[22] G. Van der Snickt, C. Miliani, K. Janssens, B.G. Brunetti, A. Romani, F. Rosi, P. Walter, J. Castaing, W. De Nolf, L. Klaassen, I. Labarque, R. Wittermann, Material analyses of "Christ with singing and musicmaking Angels", a late 15th-C panel painting attributed to Hans Memling and assistants: Part I. noninvasive in situ investigations, Journal of Analytical Atomic Spectrometry 26(11) (2011) 2216-2229.

[23] F. Rosi, R. Harig, C. Miliani, R. Braun, D. Sali, A. Daveri, B. Brunetti, A. Sgamellotti, Mid-infrared hyperspectral imaging of painting materials, Proc. SPIE 8790, Optics for Arts, Architecture, and Archaeology IV, SPIE2013, p. 87900Q.

[24] R.D. Rusu, B. Simionescu, A.V. Oancea, M. Geba, L. Stratulat, D. Salajan, L.E. Ursu, M.C. Popescu, M. Dobromir, M. Murariu, C. Cotofana, M. Olaru, Analysis and structural characterization of pigments and materials used in Nicolae Grigorescu heritage paintings, Spectrochimica Acta Part A: Molecular and Biomolecular Spectroscopy 168 (2016) 218-229.

[25] W. Vetter, M. Schreiner, Characterization of pigment-binding Media systems - Comparison of noninvasive in-situ reflection FTIR with transmission FTIR microscopy, e-PRESERVATIONScience 8 (2011) $10-22$. 
[26] D. Mancini, A. Percot, L. Bellot-Gurlet, P. Carnazza, P. Colomban, Italian Modern paintings through portable vibrational techniques, InArt 2018: 3rd International Conference on Innovation in Art Research and Technology, Parma, Italy, 2018.

[27] S. Frezzotti, I. Italiano, A. Rorro, Galleria nazionale d'arte moderna \& MAXXI : le collezioni 1958-2008, Electa, Milano, 2009.

[28] T. Learner, Modern paints, Scientific Examination of Art: Modern Techniques in Conservation and Analysis, The National Academies Press, Washington, DC, 2005, pp. 137-151.

[29] M.T. Doménech-Carbó, A. Doménech-Carbó, J.V. Gimeno-Adelantado, F. Bosch-Reig, Identification of synthetic resins used in works of Art by Fourier Transform Infrared Spectroscopy, Applied Spectroscopy 55(12) (2001) 1590-1602.

[30] S. Croll, An overview of developments in the paint industry since 1930, in: T.J.S. Learner, P. Smithen, J.W. Krueger, M.R. Schilling (Eds.), Modern paints uncovered: proceedings from the Modern Paints uncovered symposium, the Getty Conservation Institute, Los Angeles, 2007, pp. 17-29.

[31] M. Doerner, The materials of the artist and their use in painting: with notes on the techniques of the old masters, Faber, London, 1984.

[32] R. Mayer, The artist's handbook of materials and techniques, Viking, New York, 1991.

[33] F.C. Izzo, K.J. van den Berg, H. van Keulen, B. Ferriani, E. Zendri, Modern oil paints - formulations, organic additives and degradation: some case studies, in: K.J. van den Berg, A. Burnstock, M. de Keijzer, J. Krueger, T. Learner, d.A. Tagle, G. Heydenreich (Eds.), Issues in Contemporary Oil Paint, Springer International Publishing, Cham, 2014, pp. 75-104.

[34] C. Maltese, Le tecniche artistiche, Mursia, Milano, 2007, p. 549.

[35] M. Miljković, B. Bird, M. Diem, Line shape distortion effects in infrared spectroscopy, Analyst 137(17) (2012) 3954-3964.

[36] J.C. Lindon, Encyclopedia of spectroscopy and spectrometry (Second Edition), Academic Press, Oxford, 2010.

[37] C. Daher, V. Pimenta, L. Bellot-Gurlet, Towards a non-invasive quantitative analysis of the organic components in museum objects varnishes by vibrational spectroscopies: methodological approach, Talanta 129(0) (2014) 336-345.

[38] R. Ploeger, O. Chiantore, Characterization and stability issues of artists' alkyd paints, in: M.F. Mecklenburg, A.E. Charola, R.J. Koestler (Eds.), New Insights into the Cleaning of Paintings: Proceedings from the Cleaning 2010 International Conference, Smithsonian Contributions to Museum Conservation, Washington, DC, 2013, pp. 89-95.

[39] F. Casadio, C. Daher, L. Bellot-Gurlet, Raman spectroscopy of cultural heritage materials: overview of applications and new frontiers in instrumentation, sampling modalities, and data processing, Topics in Current Chemistry 374(5) (2016) 62-113.

[40] P. Vandenabeele, L. Moens, H.G.M. Edwards, R. Dams, Raman spectroscopic database of azo pigments and application to modern art studies, Journal of Raman Spectroscopy 31(6) (2000) 509-517.

[41] W. Fremout, S. Saverwyns, Identification of synthetic organic pigments: the role of a comprehensive digital Raman spectral library, Journal of Raman Spectroscopy 43(11) (2012) 1536-1544. 


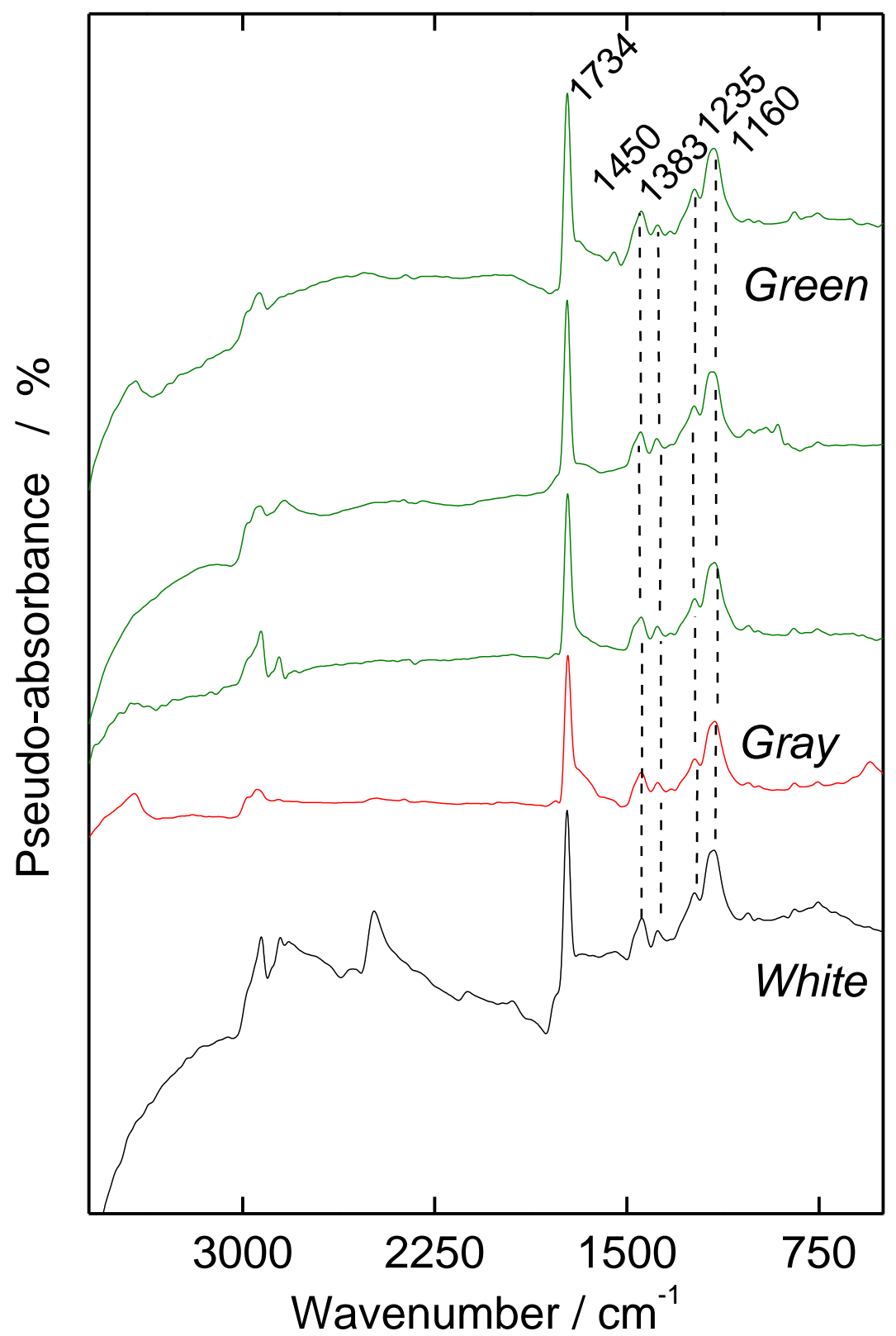

Figure 2: In situ reflection spectra with KKT correction on J. Albers "Homage to the square" painting - acrylic, see Table 1) are shown for three hues of green, gray and white colours.

Good reproducibility is obtained (3 different green spots). 


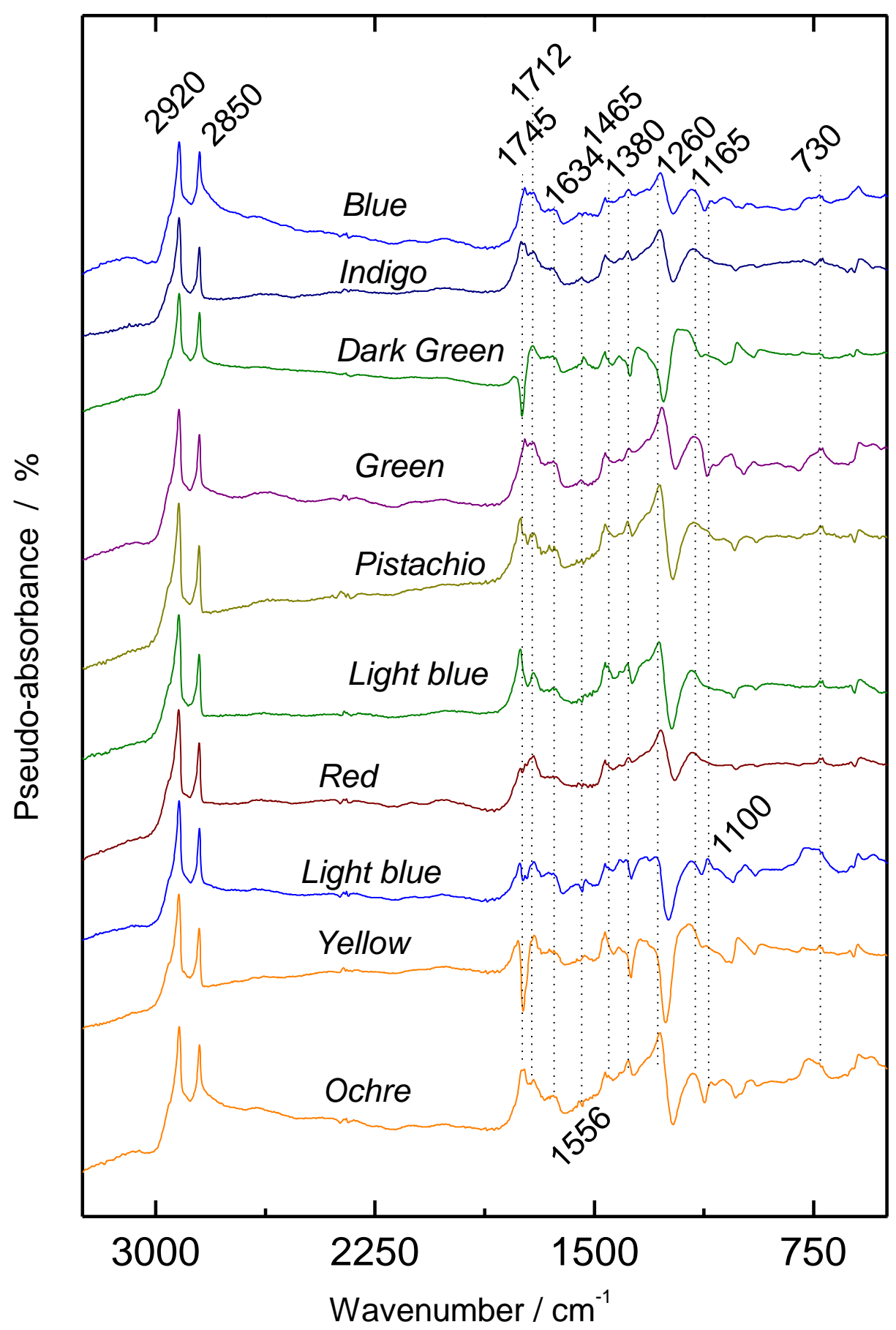

Figure 3: In situ reflection spectra with KKT correction on L. Boille "Elementare Complesso" painting (Oil, see Table 1) are shown for ten different colors. 


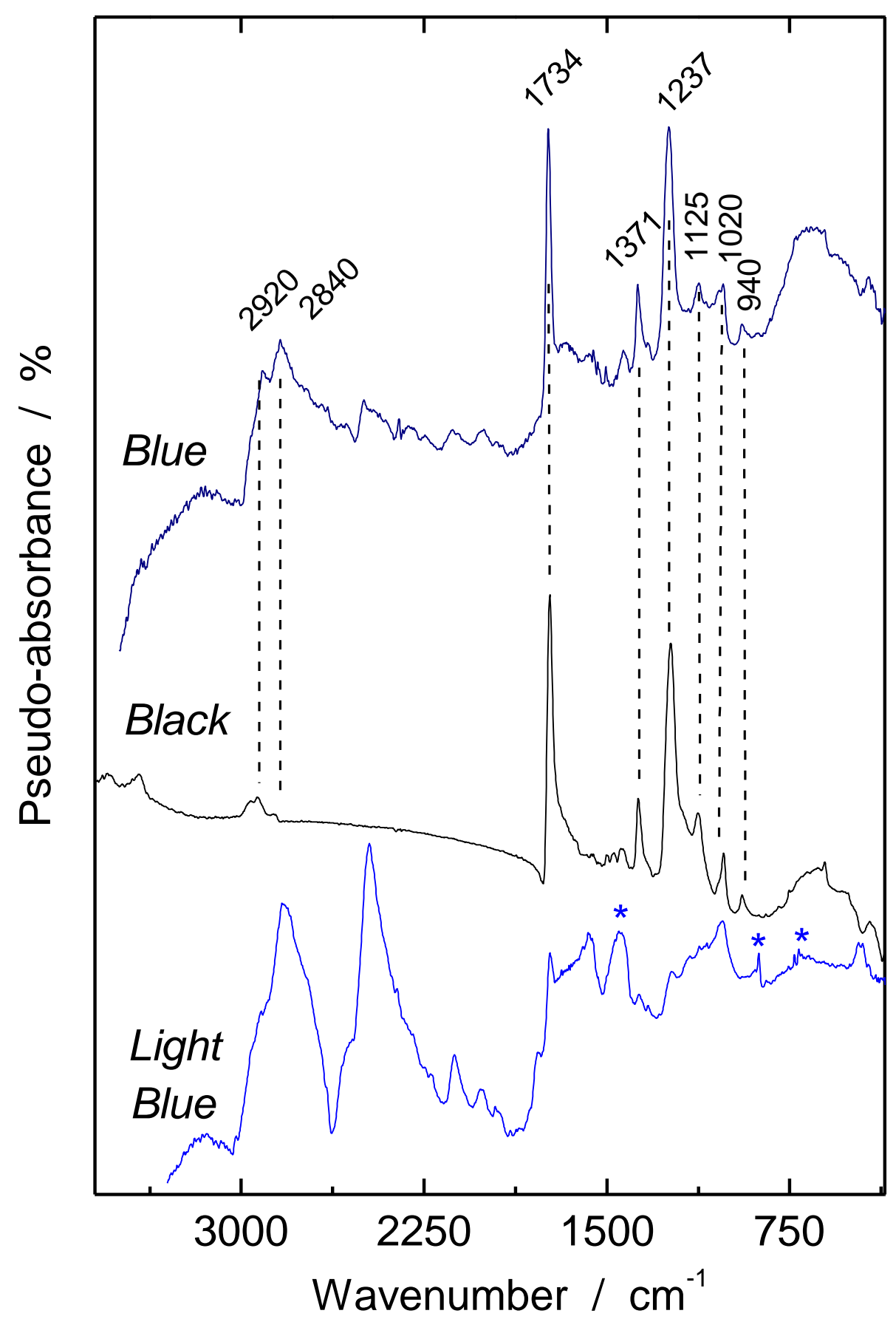

Figure 4: In situ reflection spectra with KKT correction on A. Bonalumi "Blu 13/B" (blue, acrylic), "Oggetto ${ }^{\circ} 23$ " (black, enamel) and "Azzurro" (light blue, vinylic tempera) paintings are shown. Stars (*) refer to characteristic pigment bands. 


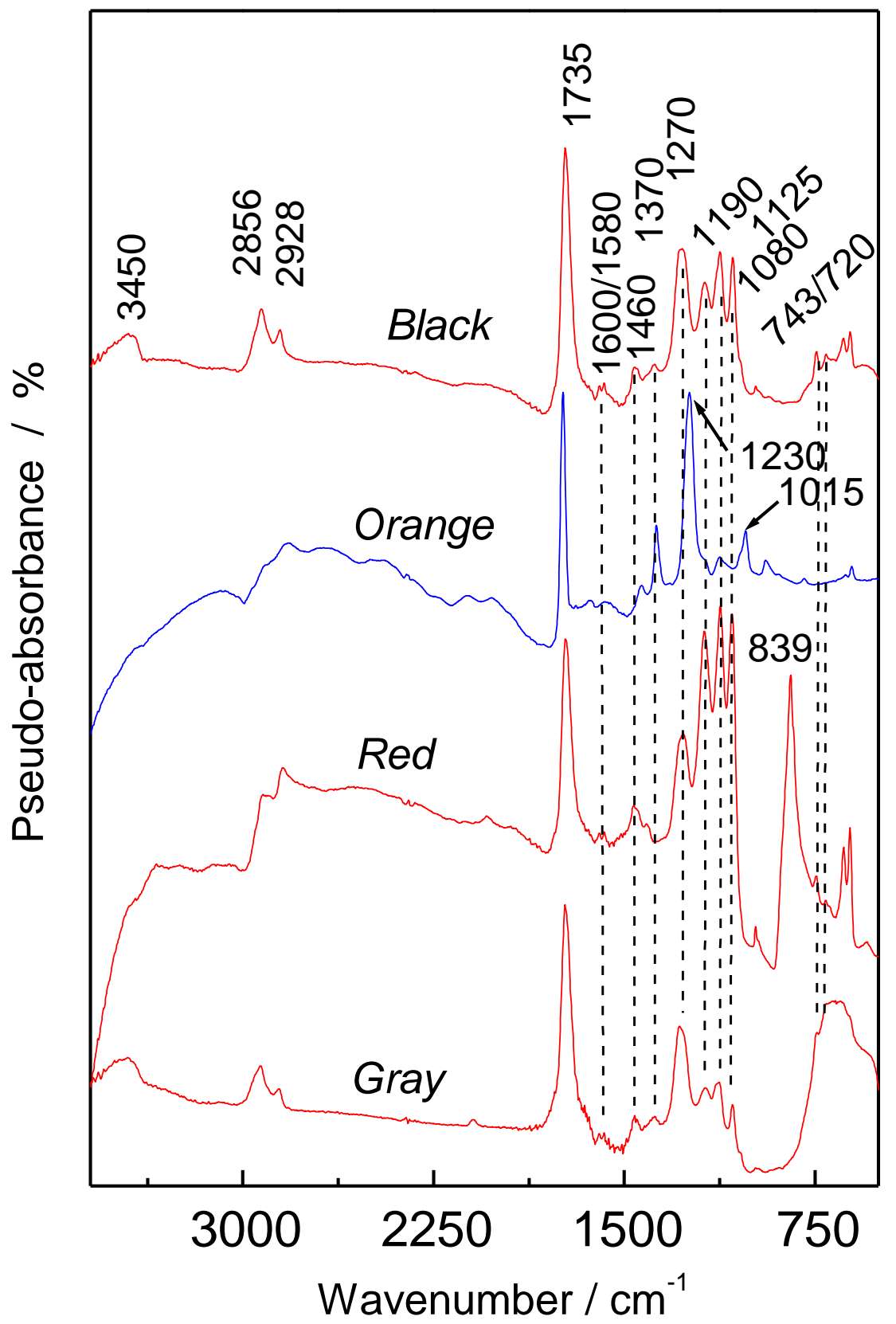

Figure 5: In situ reflection spectra with KKT correction on M. Schifano "Incidente D662" painting (enamel) are shown for four different colours. 


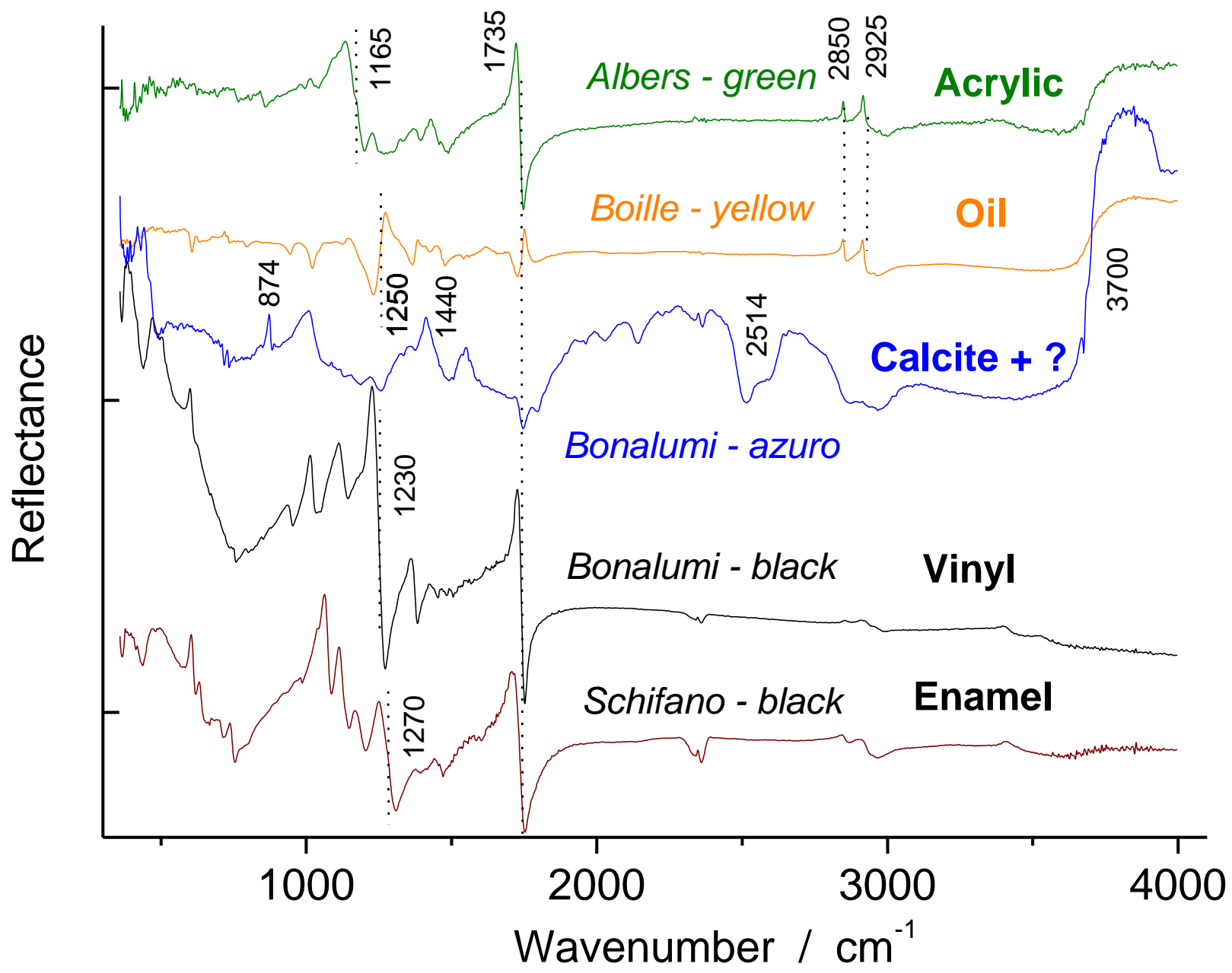

Figure 6: In situ reflection spectra are shown for the different kind of binders 


\title{
Supplementary Materials
}

\section{On-site contactless surface analysis of Modern paintings from Galleria Nazionale (Rome) by Reflectance FTIR and Raman spectroscopies}

\author{
Diana Mancini ${ }^{1,2}$, Aline Percot ${ }^{1}$, Ludovic Bellot-Gurlet ${ }^{1}$, Philippe Colomban $^{1}$, Paola Carnazza ${ }^{2}$ \\ ${ }^{1}$ Sorbonne Université, CNRS, De la Molécule aux Nano-Objets: Réactivité, Interactions et Spectroscopies, \\ MONARIS UMR8233, 4 Place Jussieu, 75005 Paris, France. \\ ${ }^{2}$ Galleria Nazionale d’Arte Moderna e Contemporanea viale delle Belle Arti 131, 00197 Roma, Italy.
}

\section{Laboratory analysis of commercial paints mock-up by reflectance IR, ATR-IR and Raman spectroscopies}

Similar spectra were obtained for all the colours based on the same binder (data not shown). The attributions of IR bands are presented in Tables S1-S4.

We can notice in various spectra intense IR bands corresponding to fillers or extenders in the form of inorganic minerals such as calcium carbonate (calcite). The addition of an opacifier could be explained by the need to adapt the refractive index and to reduce the amount of pigment needed to obtain the desired hue and decrease the cost of the final product. The sorption of dye(s) on the inorganic opacifier grain/particle also improves the colour homogeneity and gloss. As a consequence, mineral additives may constitute from 20 to $50 \%$ of the paint formulations, especially for water based paint formulations that use a maximum of mineral additives (Karakas, 2011).
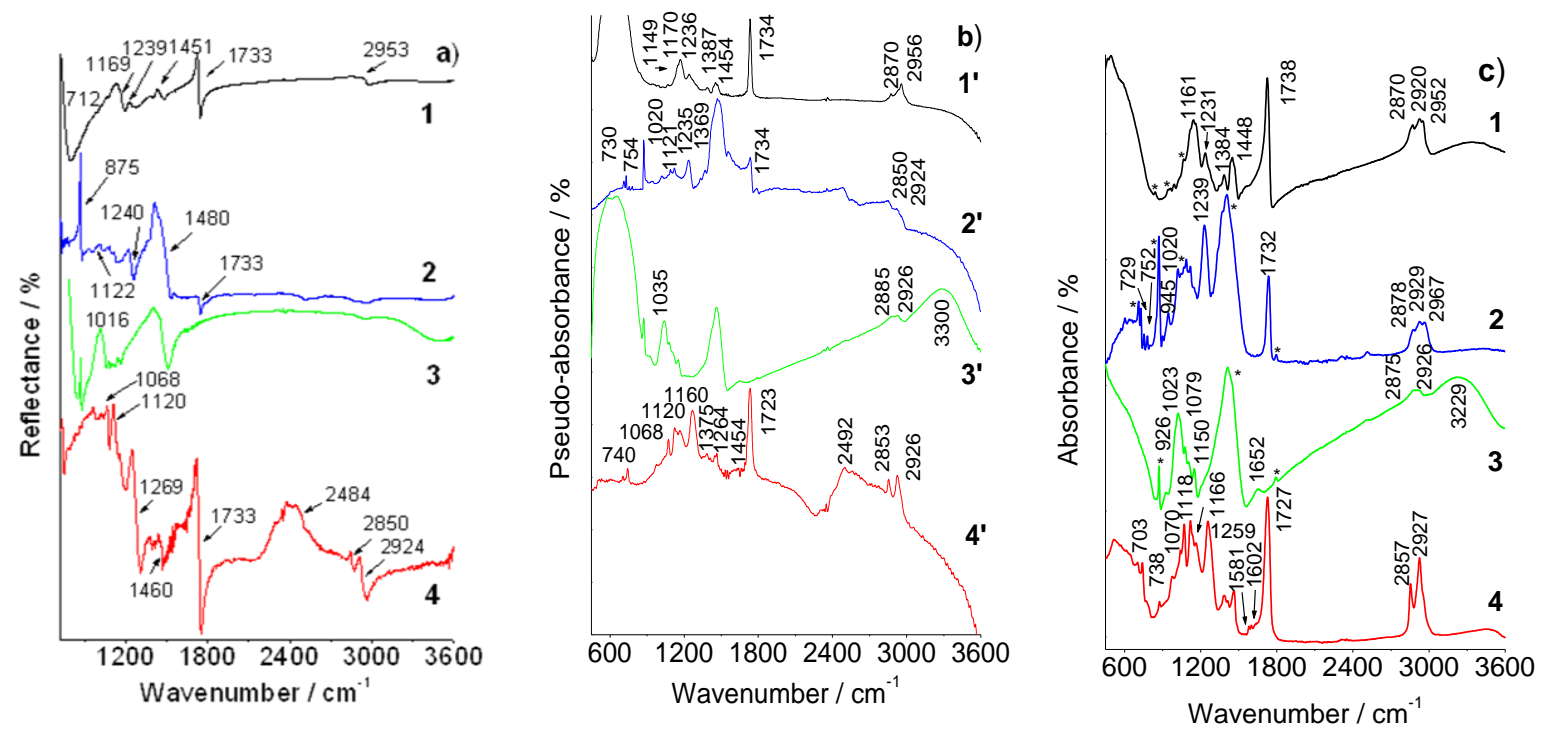

Fig S1: IR spectra from reference samples of commercial paint (1: Liquitex professional and basics ${ }^{\circledR}$ acrylic, white colour; 2: Lefranc \& Bourgeois: Flashe ${ }^{\circledR}$ vinylic, blue colour; 3: Royal Talens: extra fine quality ${ }^{\circledR}$ tempera, gray, silver colour; 4: Rainbow: retouching model enamels ${ }^{\circledR}$, enamel, white colour) are presented: a) Reflectance; b) Pseudo-absorbance (after KKT Transformation); c) ATR absorbance.

Note that spectra 2 and 3 are dominated by the IR bands of calcium carbonate at 1410,874 and $712 \mathrm{~cm}^{-1}$ (Doménech-Carbo et al., 2011). 
Mancini et al., On-site contactless surface analysis of Modern paintings from Galleria Nazionale (Rome) by Reflectance FTIR and Raman spectroscopies.

\begin{tabular}{|c|c|c|}
\hline \multicolumn{2}{|c|}{ Main IR characteristic bands for acrylic binder } \\
\hline ATR $\left(\mathrm{cm}^{-1}\right)$ & $\mathrm{SR}\left(\mathrm{cm}^{-1}\right)$ & $\begin{array}{c}\text { Suggested } \\
\text { assignments }\end{array}$ \\
\hline $2952,2920,2870$ & $2956,2924,2870$ & $v \mathrm{CH}_{3,}, \mathrm{VH}_{2}$ \\
\hline 1738 & 1734 & $v \mathrm{C}=\mathrm{O}$ \\
\hline 1448 & 1454 & $\delta \mathrm{CH}\left(\mathrm{CH}_{3}, \mathrm{CH}_{2}\right)$ \\
\hline 1384 & 1387 & $\delta \mathrm{CH}\left(\mathrm{CH}_{3}, \mathrm{CH}_{2}\right)$ \\
\hline 1231 & 1236 & $v \mathrm{C}-\mathrm{C}(=\mathrm{O})-\mathrm{O}$ \\
\hline 1161 & 1170 & $\mathrm{vC}-\mathrm{O}$ \\
\hline
\end{tabular}

Table S1: Positions and suggested assignments of IR bands for the acrylic reference sample of commercial paint Liquitex professional and basics ${ }^{\circledR}$ acrylic, white colour (Chercoles Asensio et al., 2009; DoménechCarbo et al., 2011).

\begin{tabular}{|c|c|c|}
\hline \multicolumn{3}{|c|}{ Main IR characteristic bands for poly(vinylacetate) binder } \\
\hline ATR $\left(\mathrm{cm}^{-1}\right)$ & $\mathrm{SR}\left(\mathrm{cm}^{-1}\right)$ & Suggested assignments \\
\hline $\mathbf{2 9 6 7 , 2 9 2 9 , 2 8 7 8}$ & 2924,2850 & $\mathrm{vCH}_{3}, \nu \mathrm{CH}_{2}$ \\
\hline $\mathbf{1 7 3 2}$ & 1734 & $v \mathrm{C}=\mathrm{O}$ \\
\hline $\mathbf{1 3 7 0}$ & 1369 & $\delta \mathrm{CH}$ \\
\hline $\mathbf{1 2 3 9}$ & 1235 & $v \mathrm{C}-\mathrm{C}(=\mathrm{O})-\mathrm{O}$ \\
\hline $\mathbf{1 1 1 9}$ & 1121 & $\mathrm{vC}-\mathrm{O}, \delta \mathrm{C}=\mathrm{O}, \delta \mathrm{CH}$ \\
\hline $\mathbf{1 0 2 0}$ & 1020 & $\mathrm{v}-\mathrm{O}-\mathrm{C}-, \delta \mathrm{CH}_{3}, \delta \mathrm{CH}_{2}$ \\
\hline
\end{tabular}

Table S2: Positions and suggested assignments of IR bands for the vinylic (PVAc) reference sample of commercial paint Lefranc \& Bourgeois: Flashe ${ }^{\circledR}$ vinylic, blue colour (Chercoles Asensio et al.,2009; Doménech-Carbo et al., 2011).

\begin{tabular}{|c|c|c|}
\hline \multicolumn{3}{|c|}{ Main IR characteristic bands for tempera binder } \\
\hline $\operatorname{ATR}\left(\mathrm{cm}^{-1}\right)$ & $\mathrm{SR}\left(\mathrm{cm}^{-1}\right)$ & Suggested assignments \\
\hline 3229 & 3300 & vOH in polysaccaryde \\
\hline 2926,2875 & 2926,2885 & $v \mathrm{CH}_{3}, v \mathrm{CH}_{2}$ \\
\hline 1079 & & $v \mathrm{C}-\mathrm{C}, \mathrm{vC}-\mathrm{O}$ \\
\hline 1021 & 1035 & in pyranose ring \\
\hline
\end{tabular}

Table S3: Positions and suggested assignments of IR bands for the "fine tempera" reference sample of commercial paint Royal Talens: extra fine quality ${ }^{\circledR}$ tempera, gray, silver colour (Zaffino et al., 2015, GómezOrdóñez et al., 2011).

\begin{tabular}{|c|c|c|}
\hline \multicolumn{3}{|c|}{ Main IR characteristic bands for Enamel binder } \\
\hline ATR $\left(\mathrm{cm}^{-1}\right)$ & $\mathrm{SR}\left(\mathrm{cm}^{-1}\right)$ & Suggested assignments \\
\hline $\mathbf{2 9 2 7}, \mathbf{2 8 5 7}$ & 2926,2853 & $\mathrm{CH}_{3}, \mathrm{CH}_{2}$ \\
\hline $\mathbf{1 7 2 7}$ & 1735 & $\mathrm{vC}=\mathrm{O}$ in ester \\
\hline $\mathbf{1 6 0 2}$ & 1607 & $v$ aromatic ring \\
\hline $\mathbf{1 5 8 1}$ & 1583 & $v$ aromatic ring \\
\hline 1465 & & $\delta \mathrm{CH}_{2}$ \\
\hline 1259 & 1266 & $\delta \mathrm{CH}, v \mathrm{C}-\mathrm{C}, \mathrm{vC}-\mathrm{O}$ \\
\hline 1118 & 1123 & $\delta \mathrm{CH}, \mathrm{CC}-\mathrm{C}, \mathrm{vC}-\mathrm{O}$ \\
\hline 1070 & 1072 & $\begin{array}{c}\text { Unsaturated aromatic } \\
\text { in plane def. }\end{array}$ \\
\hline $\mathbf{7 4 0 , 7 0 1}$ & 743,703 & Aromatic out of plane bending \\
\hline
\end{tabular}

Table S4: Positions and suggested assignments of IR bands for the enamel reference sample of commercial paint Rainbow: retouching model enamels ${ }^{\circledR}$, enamel, white colour (Ploeger et al., 2008; Duce et al., 2014). 


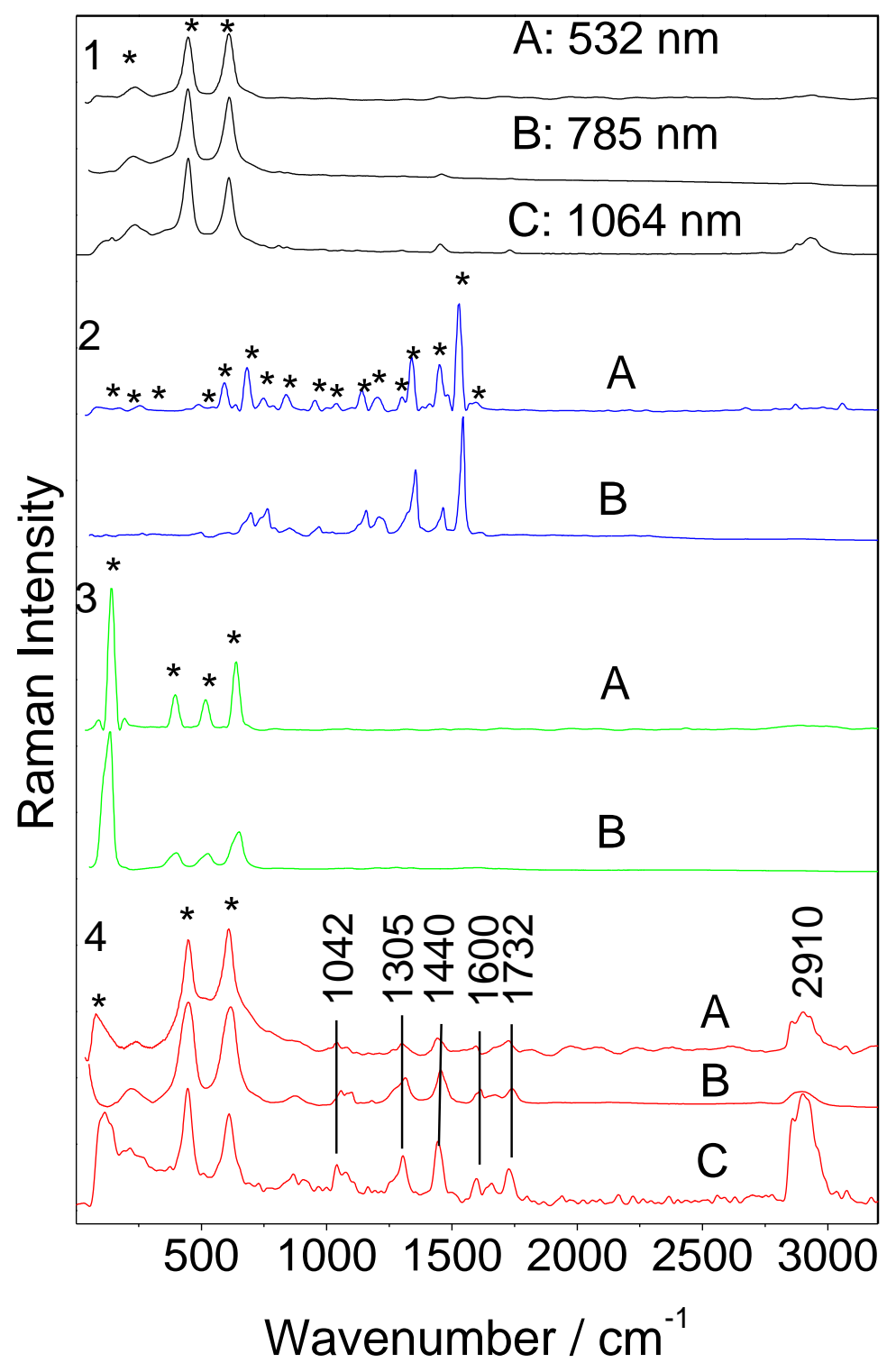

Fig. S2: Raman spectra registered on reference samples of commercial paints:

Raman spectra registered on reference samples of commercial paints (1: Liquitex professional and basics $^{\circledR}$ acrylic, white colour; 2: Lefranc \& Bourgeois: Flashe ${ }^{\circledR}$ vinylic, blue colour; 3: Royal Talens: extra fine quality $^{\circledR}$ tempera, gray, silver colour; 4: Rainbow: retouching model enamels ${ }^{\circledR}$, enamel, white colour) with several excitation wavelengths $(\lambda)$ : $532 \mathrm{~nm}(\mathrm{~A}), 785 \mathrm{~nm}$ (B) and $1064 \mathrm{~nm}$ (C) after baseline subtraction. Stars $(*)$ refer to characteristic pigment bands.

Stars $\left({ }^{*}\right)$ refer to characteristic inorganic rutile, anatase and organic PB15 pigment bands.

\begin{tabular}{|c|c|c|c|c|}
\hline \multicolumn{4}{|c|}{ Wavenumbers $\left(\mathrm{cm}^{-1}\right)$} & \multirow{2}{*}{$\begin{array}{c}\text { Suggested } \\
\text { assignments }\end{array}$} \\
\cline { 2 - 5 } IR Absorbance/bands & $532 \mathrm{~nm}$ & $785 \mathrm{~nm}$ & $1064 \mathrm{~nm}$ & \\
\hline $\mathbf{2 9 2 7 , 2 8 5 7}$ & 2926,2903 & 2895 & 2959,2899 & $v^{2} \mathrm{CH}_{3,}, \mathrm{CH}_{2}$ \\
\hline $\mathbf{1 7 2 7}$ & 1727 & 1741 & 1727 & $v \mathrm{C}=\mathrm{O}$ in ester \\
\hline $\mathbf{1 6 0 0}$ & 1596 & 1613 & 1596 & $\begin{array}{c}v \mathrm{C}=\mathrm{C} \text { aromatic C- } \\
\mathrm{C} \text { stretching } \\
\text { vibrations }\end{array}$ \\
\hline 1462 & 1443 & 1455 & 1443 & $\delta \mathrm{CH}_{2}$ \\
\hline 1070 & 1297 & 1314 & 1303 & $\delta \mathrm{CH}_{\text {in }}$ plane \\
\hline & & 1065 & 1044 & $\begin{array}{c}\text { unsaturated } \\
\text { aromatic in plane } \\
\text { deformation }\end{array}$ \\
\hline
\end{tabular}

Table S5: Positions and suggested assignments of Raman bands for the enamel reference sample of commercial paint (Rainbow, white; Fig. S2-4). 
Mancini et al., On-site contactless surface analysis of Modern paintings from Galleria Nazionale (Rome) by Reflectance FTIR and Raman spectroscopies.

II. On-site analysis of sample paintings from Galleria Nazionale (Rome) by reflectance IR and Raman spectroscopies

II.a. On-site analysis of Scialoja painting by reflectance IR spectroscopy

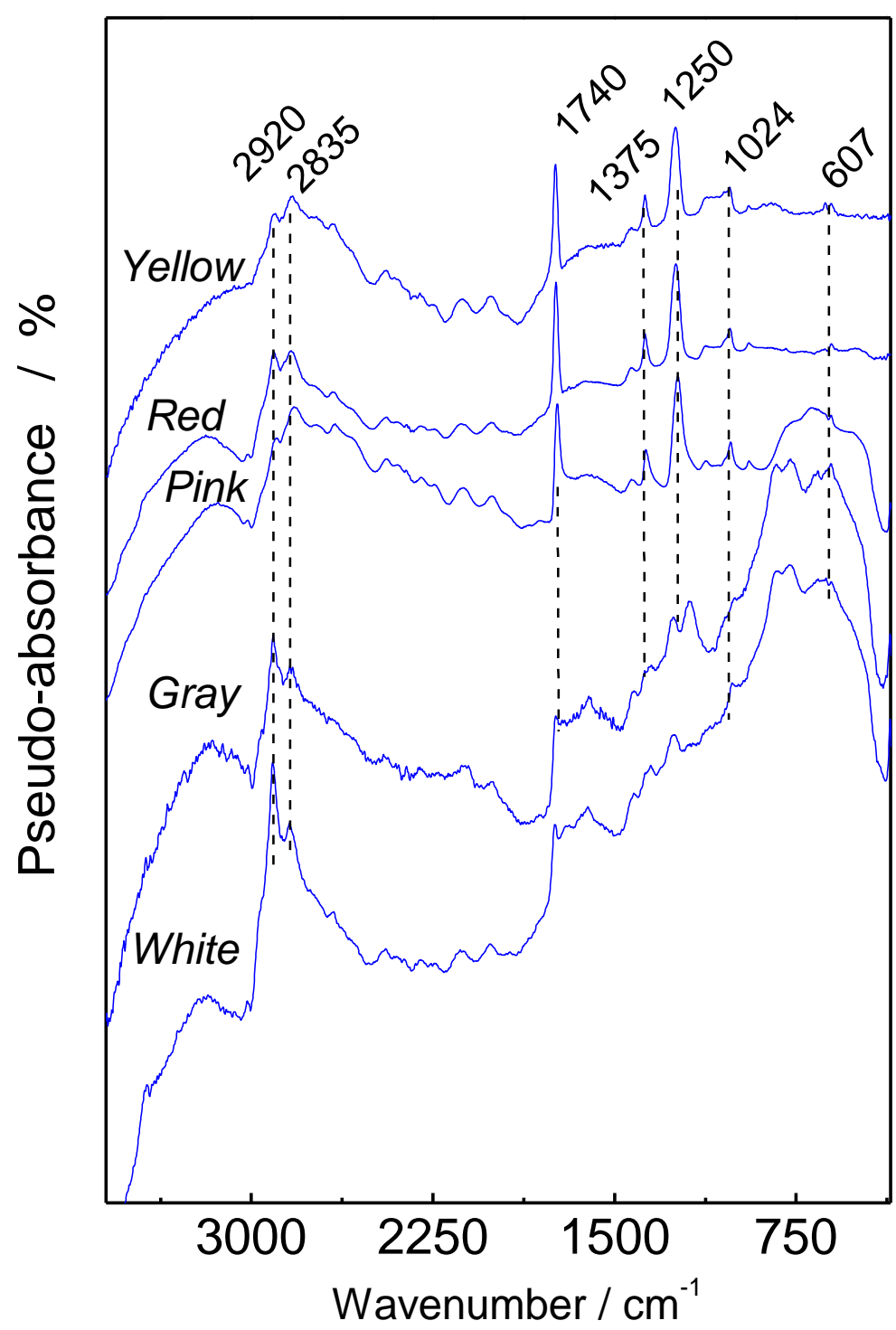

Fig. S3: In situ reflection spectra with KKT correction on Toti Scialoja "Intermittenze 1-2-3" paintings (vinylic) are shown for five different colours. 
Mancini et al., On-site contactless surface analysis of Modern paintings from Galleria Nazionale (Rome) by Reflectance FTIR and Raman spectroscopies.

II.b. On-site analysis of sample paintings from Galleria Nazionale (Rome) by Raman spectroscopy

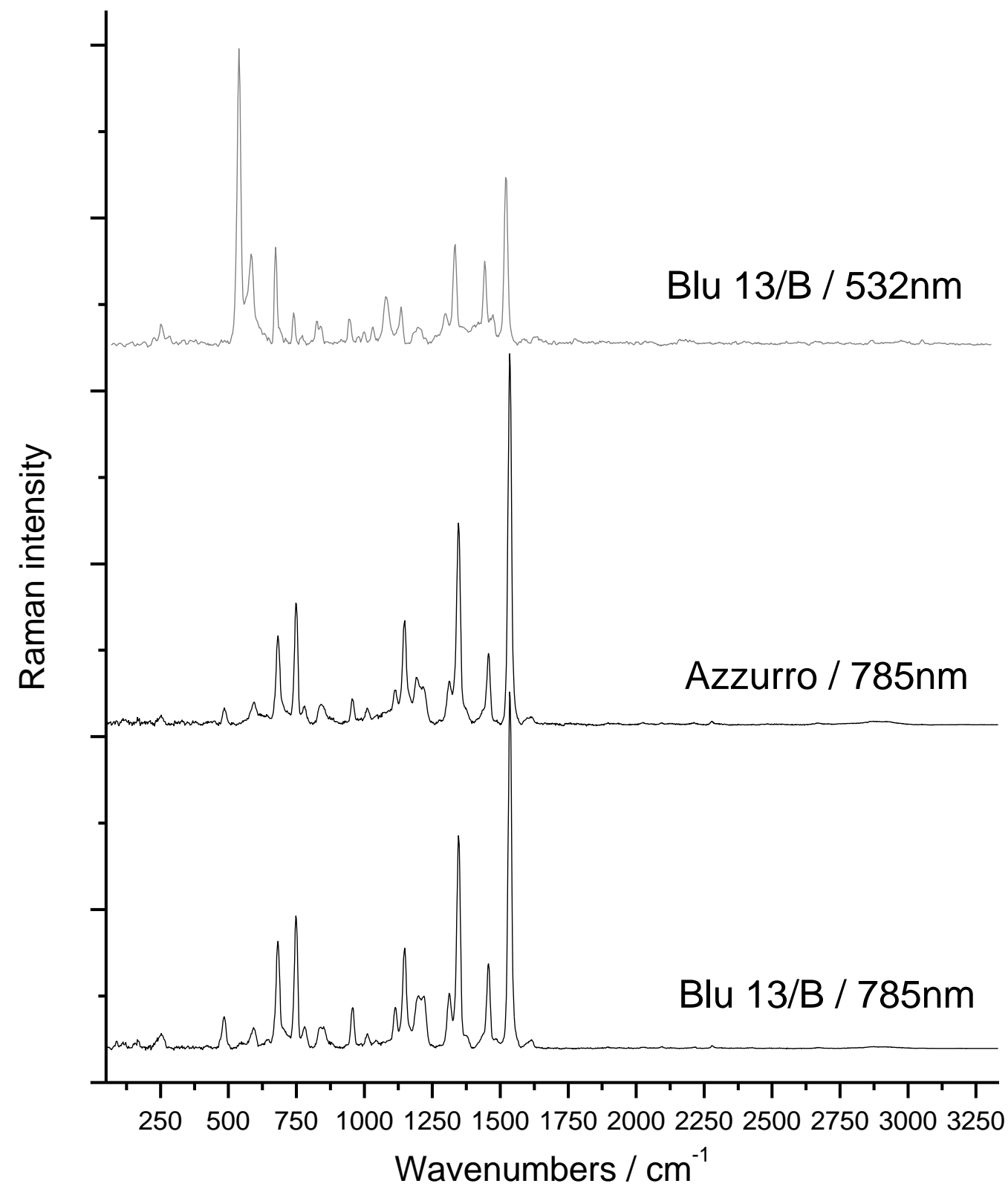

Fig.

S4:

Representati

ve Raman

spectra

obtained

from

Agostino

Bonalumi

"Blu 13/B"

(532 and

$785 \mathrm{~nm}$

excitation)

and

"Azzurro"

$1785 \mathrm{~nm}$

excitation).

Spectra

corrected

from Edge

filter

contribution

and

fluorescence

background. 
Mancini et al., On-site contactless surface analysis of Modern paintings from Galleria Nazionale (Rome) by Reflectance FTIR and Raman spectroscopies.

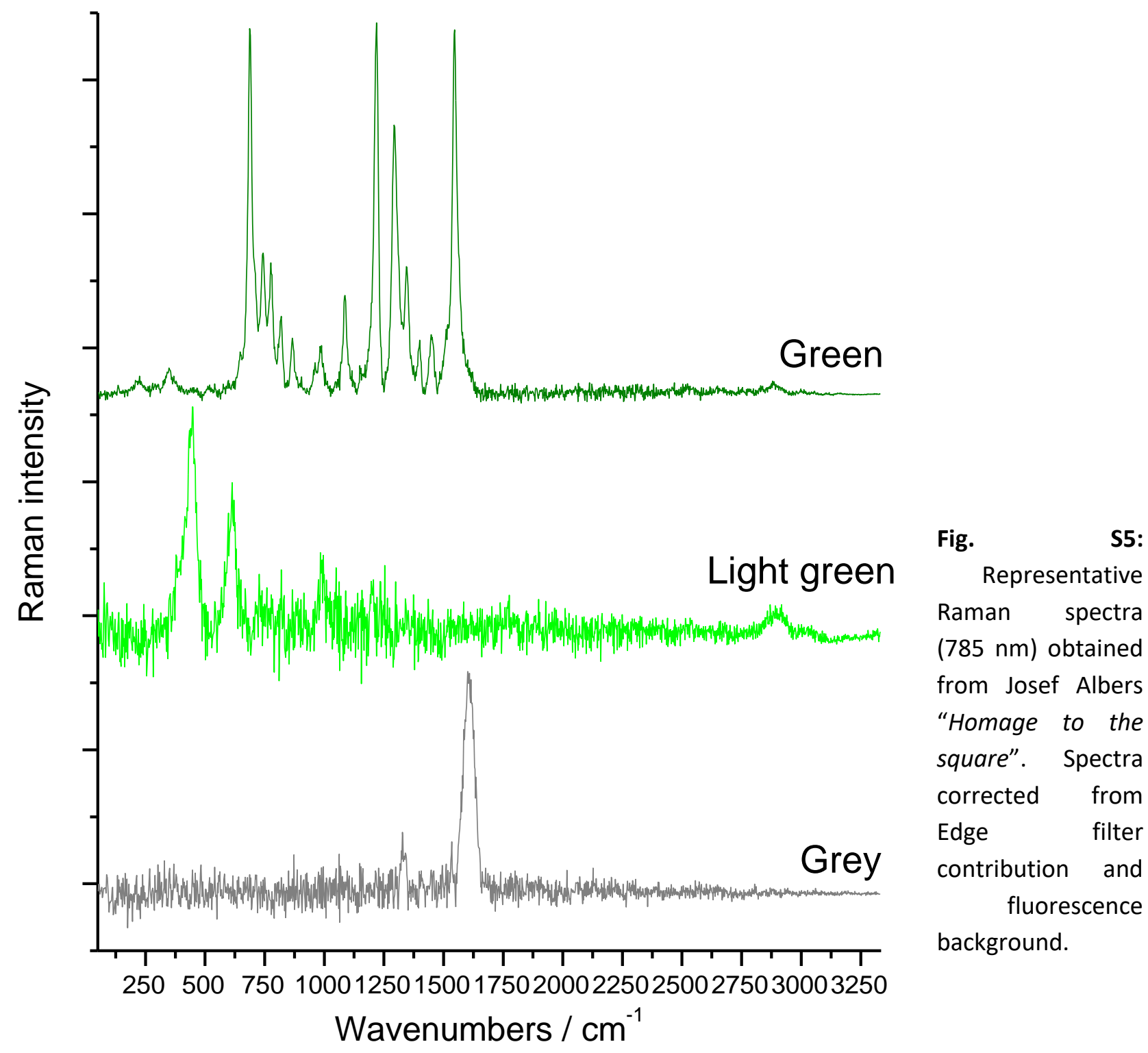


Mancini et al., On-site contactless surface analysis of Modern paintings from Galleria Nazionale (Rome) by Reflectance FTIR and Raman spectroscopies.

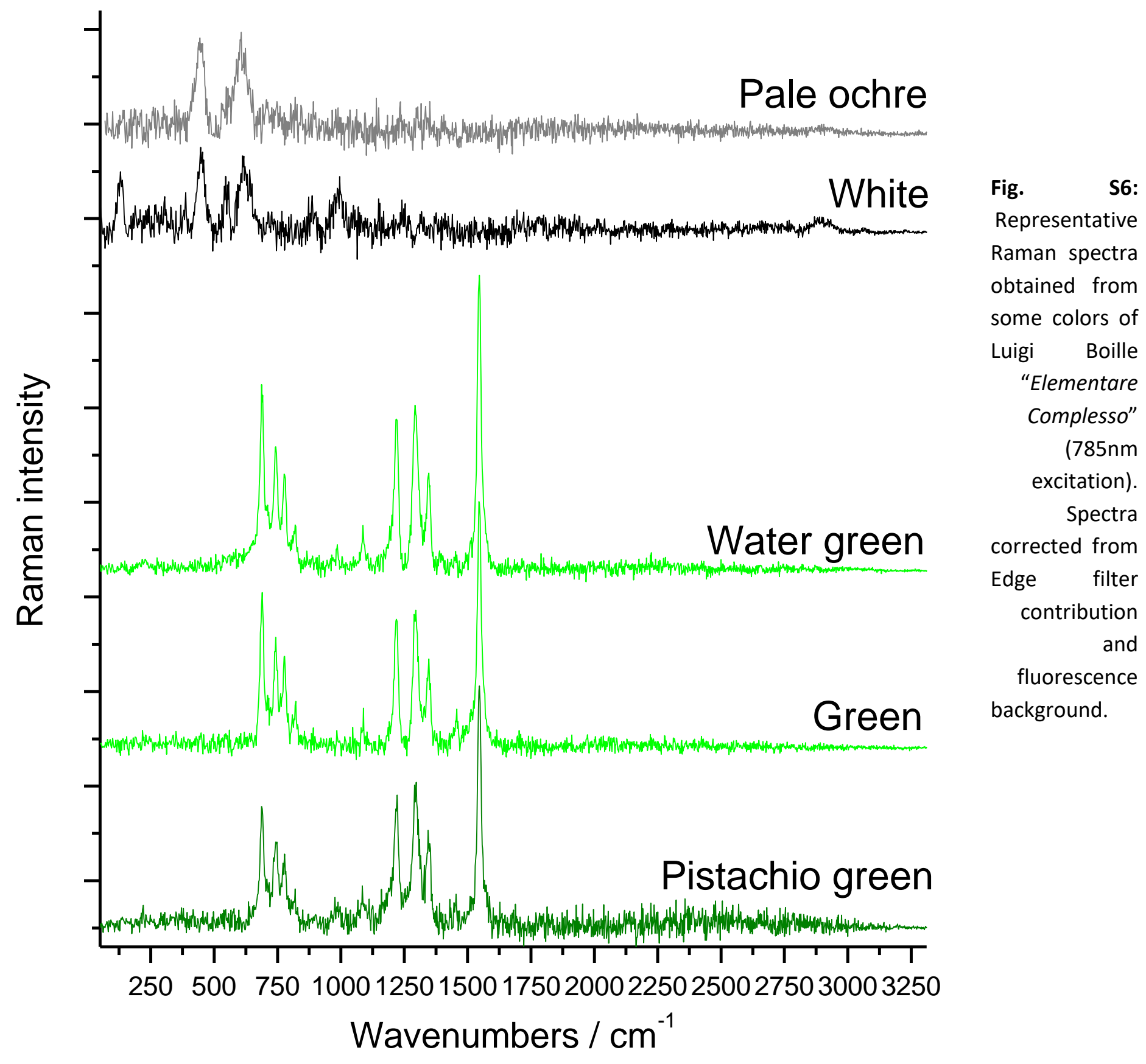




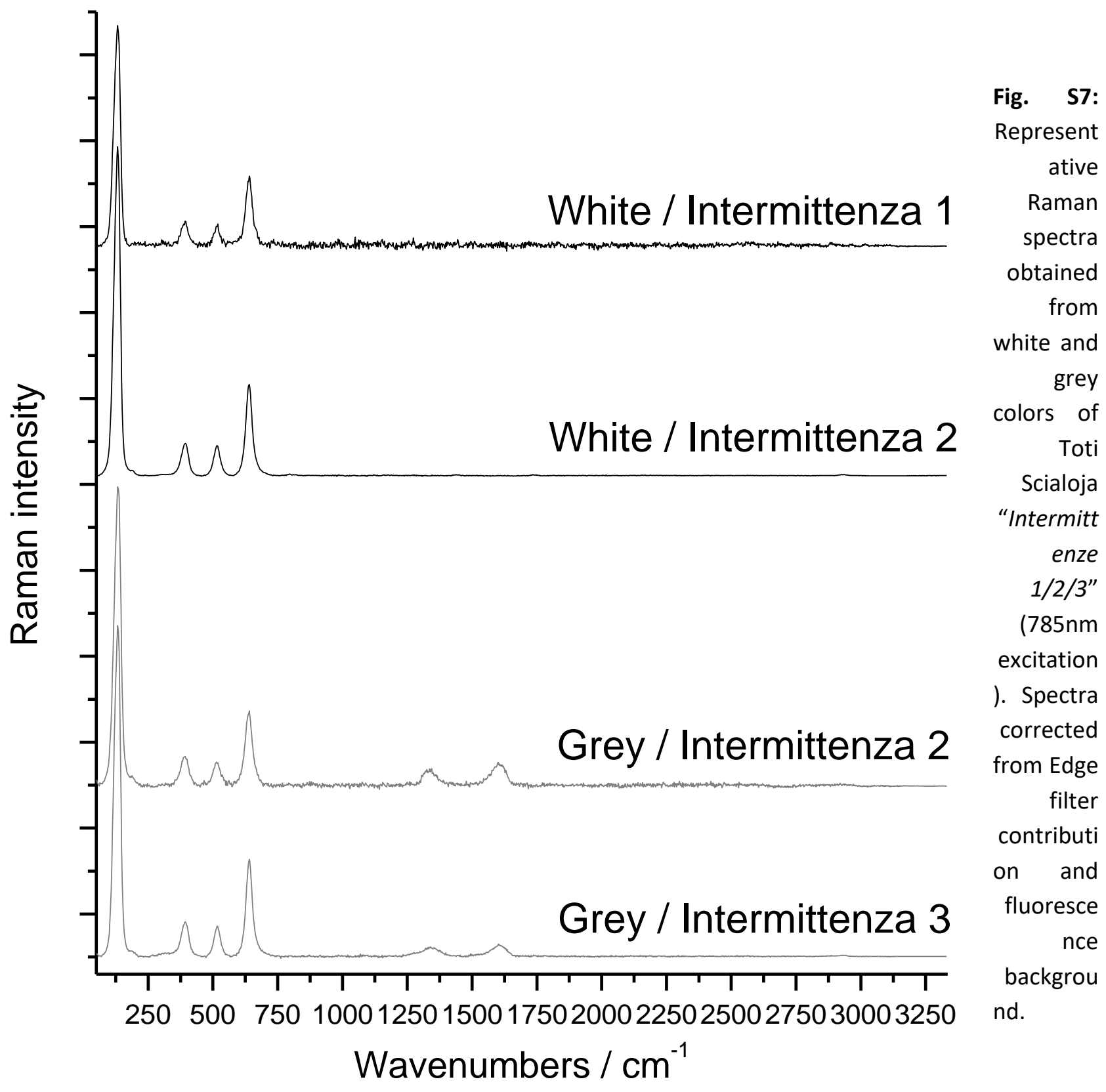


Mancini et al., On-site contactless surface analysis of Modern paintings from Galleria Nazionale (Rome) by Reflectance FTIR and Raman spectroscopies.

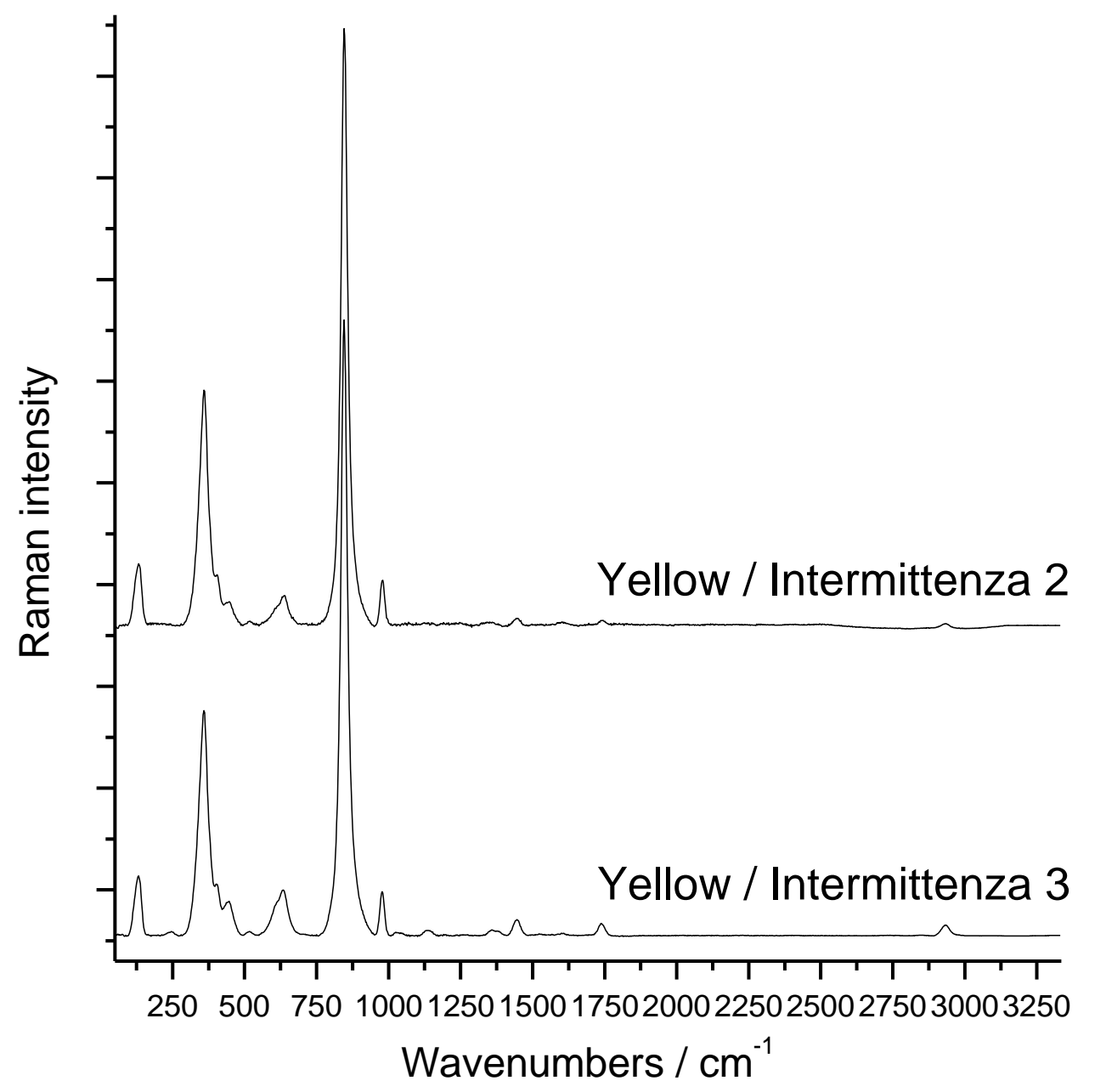

Fig.

S8:

Representative Raman spectra obtained from yellow color of Toti Scialoja "Intermittenze 2/3" (785nm excitation). Spectra corrected from Edge filter contribution and fluorescence background. 


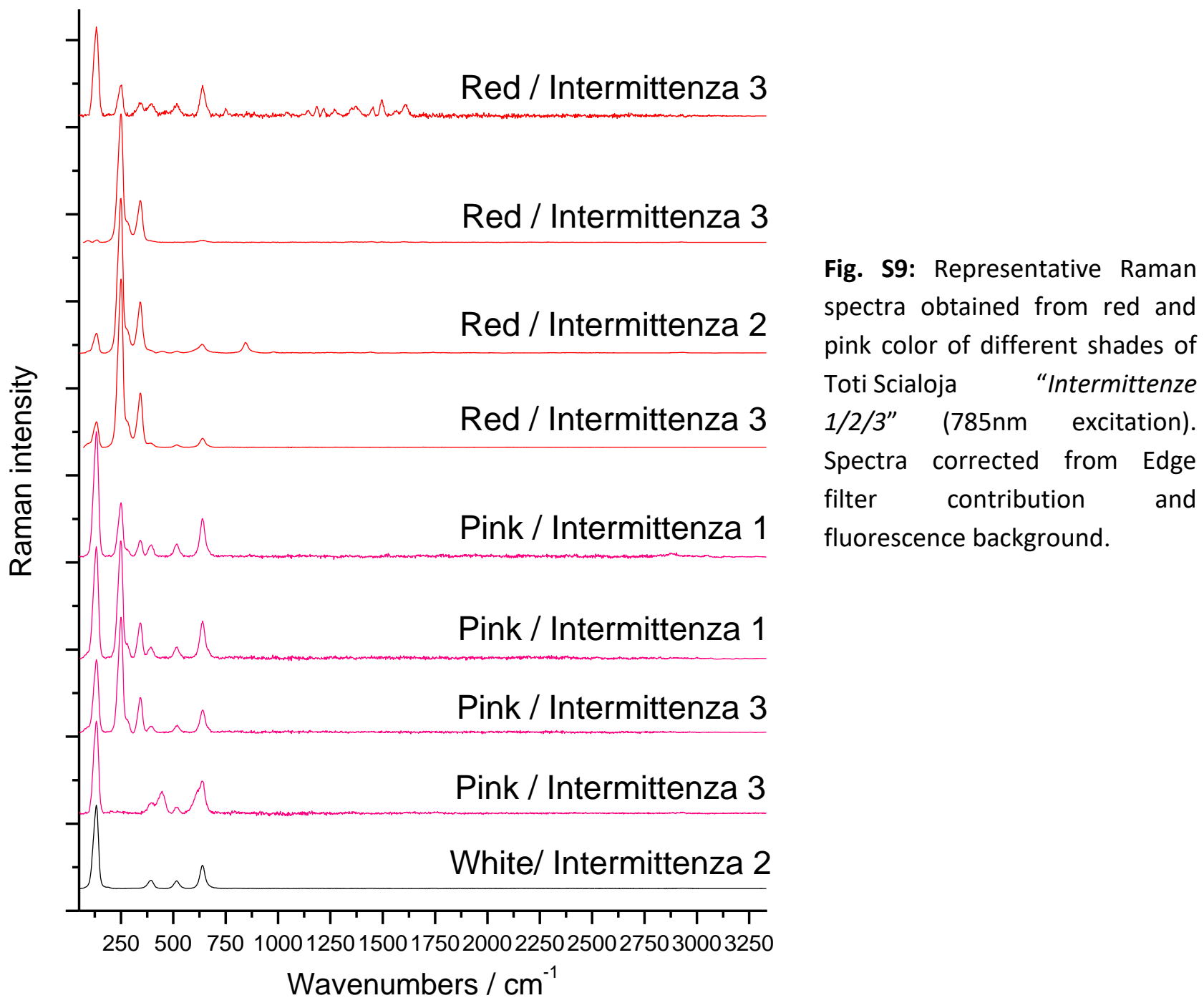


Mancini et al., On-site contactless surface analysis of Modern paintings from Galleria Nazionale (Rome) by Reflectance FTIR and Raman spectroscopies.

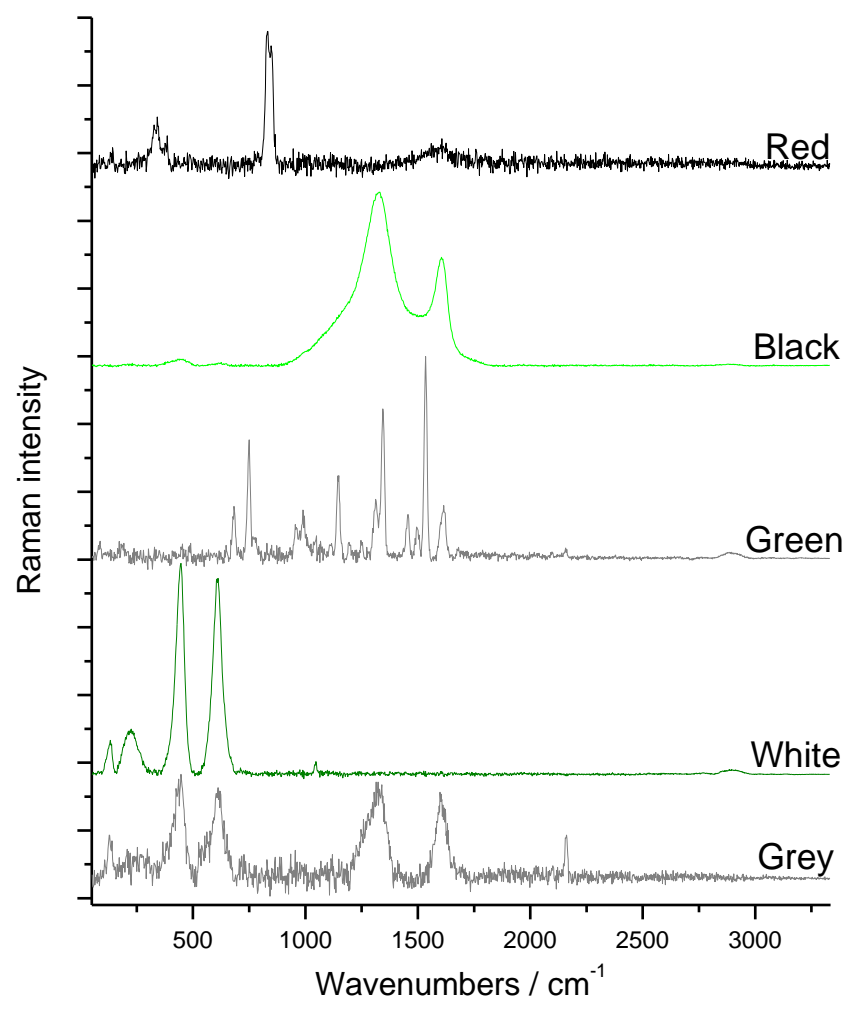

Fig. S10: Raman signatures of black, green, white, gray and red colors of Mario Schifano "Incidente D662" painting. Spectra were registered with $785 \mathrm{~nm}$ excitation wavelength, corrected from Edge filter contribution and fluorescence background.

\begin{tabular}{|c|c|c|c|}
\hline Paintings: Author & Name & Color & Pigment(s) \\
\hline \multirow{2}{*}{ Josef Albers } & \multirow{2}{*}{ Homage to the square } & Green & PG7 (phthalocyanine) with rutile for light green \\
\hline & & Grey & Carbon black \\
\hline \multirow{3}{*}{ Agostino Bonalumi } & Blu 13/B & Blue & PB15 (phthalocyanine) \\
\hline & Azzurro & Blue & PB15 (phthalocyanine) \\
\hline & Oggetto n. 23 & Blue & PB15 (phthalocyanine) \\
\hline \multirow{5}{*}{ Toti Scialoja } & \multirow{5}{*}{ Intermittenze 1-2-3 } & White & Anatase \\
\hline & & Grey & Anatase and carbon black \\
\hline & & Yellow & PY34 (chrome yellow) and little anatase \\
\hline & & Red & Vermillon (cinnabar) \\
\hline & & Pink (various shades) & Vermillon (cinnabar) and anatase \\
\hline \multirow{3}{*}{ Luigi Boille } & \multirow{3}{*}{ Elementare Complesso } & Pale ochre & Rutile \\
\hline & & White & Rutile and anatase \\
\hline & & Green (various shades) & PG7 (phthalocyanine) with rutile for light green \\
\hline \multirow{5}{*}{ Mario Schifano } & \multirow{5}{*}{ Incidente D662 } & Red & PO21 (chrome orange) \\
\hline & & Black & Carbon black \\
\hline & & Green & PB15 (phthalocyanine) and PY212 (Azo metal salt) \\
\hline & & White & Rutile \\
\hline & & Grey & Rutile and carbon black \\
\hline
\end{tabular}

Table S6: Summary of pigments identified by Raman spectroscopy. 
Mancini et al., On-site contactless surface analysis of Modern paintings from Galleria Nazionale (Rome) by Reflectance FTIR and Raman spectroscopies.

\section{References}

R. Chércoles Asensio, M. San Andrés Moya, J.M. de la Roja, M. Gómez, Analytical characterization of polymers used in conservation and restoration by ATR-FTIR spectroscopy, Analytical and Bioanalytical Chemistry, 395(7) (2009) 2081-2096.

M.T. Doménech-Carbó, M.F. Silva, E. Aura-Castro, L. Fuster-López, S. Kröner, M.L. Martínez-Bazán, X. Más-Barberá, M.F. Mecklenburg, L. Osete-Cortina, A. Doménech, J.V. Gimeno-Adelantado, D.J. Yusá-Marco, Study of behaviour on simulated daylight ageing of artists' acrylic and poly(vinyl acetate) paint films, Analytical and Bioanalytical Chemistry, 399 (2011) 2921-2937.

C. Duce, V. Della Porta, M.R. Tiné, A. Spepi, L. Ghezzi, M.P. Colombini, E. Bramanti, FTIR study of ageing of fast drying oil colour (FDOC) alkyd paint replicas, Spectrochimica Acta Part A: Molecular and Biomolecular Spectroscopy, 130 (2014) 214-221.

E. Gómez-Ordóñez, P. Rupérez, FTIR-ATR spectroscopy as a tool for polysaccharide identification in edible brown and red seaweeds, Food Hydrocolloids, 25 (2011) 1514-1520.

F. Karakaş, B.V. Hassas, K. Özhan, F. Boylu, M.S. Çelik, Calcined kaolin and calcite as a pigment and substitute for $\mathrm{TiO}_{2}$ in water based paints, XIV Balkan Mineral Processing Congress (2011).

R. Ploeger, D. Scalarone, O. Chiantore, The characterization of commercial artists' alkyd paints, Journal of Cultural Heritage, 9 (2008) 412-419.

C. Zaffino, V. Guglielmi, S. Faraone, A. Vinaccia, S. Bruni, Exploiting external reflection FTIR spectroscopy for the in-situ identification of pigments and binders in illuminated manuscripts. Brochantite and posnjakite as a case study, Spectrochimica Acta Part A: Molecular and Biomolecular Spectroscopy, 136 (2015) 1076-1085. 